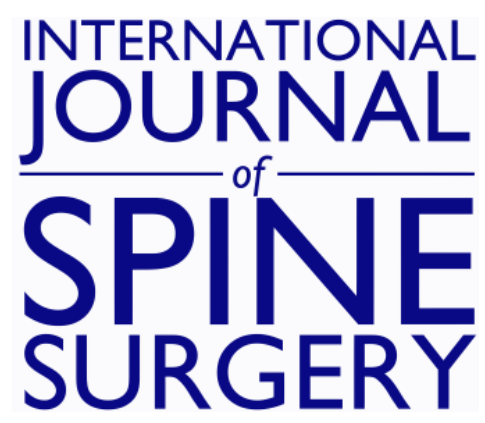

\title{
A Differential Clinical Benefit Examination of Full Lumbar Endoscopy vs Interspinous Process Spacers in the Treatment of Spinal Stenosis: An Effect Size Meta-Analysis of Clinical Outcomes
}

Kai-Uwe Lewandrowski, Ivo Abraham, Jorge Felipe Ramírez León, Roberto Cantú-Leal, Roberto Cantú Longoria, José Antonio Soriano Sánchez and Anthony Yeung

Int J Spine Surg published online 17 February 2022

http://ijssurgery.com/content/early/2022/03/01/8200

This information is current as of April 26, 2023.

Email Alerts Receive free email-alerts when new articles cite this article. Sign up at:

http://ijssurgery.com/alerts

The International Journal of Spine Surgery

2397 Waterbury Circle, Suite 1,

Aurora, IL 60504, Phone: +1-630-375-1432 


\title{
A Differential Clinical Benefit Examination of Full Lumbar Endoscopy vs Interspinous Process Spacers in the Treatment of Spinal Stenosis: An Effect Size Meta-Analysis of Clinical Outcomes
}

\author{
KAI-UWE LEWANDROWSKI ${ }^{1,2,3}$; IVO ABRAHAM, PHD ${ }^{4}$; JORGE FELIPE RAMÍREZ LEÓN, MD ${ }^{5,6}$; \\ ROBERTO CANTÚ-LEAL, MD ${ }^{5,7,8}$; ROBERTO CANTÚ LONGORIA, MD ${ }^{8}$; JOSÉ ANTONIO SORIANO SÁNCHEZ ${ }^{9,10,11}$; \\ AND ANTHONY YEUNG ${ }^{12,13}$ \\ ${ }^{I}$ Center for Advanced Spine Care of Southern Arizona and Surgical Institute of Tucson, Tucson, AZ, USA; ${ }^{2}$ Department Orthopaedic Surgey, UNIRIO, Rio de Janeiro, \\ Brazil; ${ }^{3}$ Orthopaedic Surgery, Fundación Universitaria Sanitas, Clínica Reina Sofía - Clínica Colsanitas, Bogotá, DC, USA; ${ }^{4}$ Pharmacy Practice and Science, Family \\ and Community Medicine, Clinical Translational Sciences, University of Arizona, Tucson, AZ, USA; ${ }^{5}$ Centro de Columna - Cirugía Mínima Invasiva, Bogotá, DC, \\ USA $;{ }^{6}$ Fundación Universitaria Sanitas, Bogotá, DC, USA $;{ }^{7}$ Clínica Reina Sofía-Clínica Colsanitas, Bogotá, DC, USA; ${ }^{8}$ Department of Spine Surgery, Hospital \\ Christus Muguerza Alta Especialidad in Monterrey, Monterrey, Mexico; ${ }^{9}$ Asociación Mexicana de Cirujanos de Columna, AMCICO, Ciudad de Mexico, Mexico; \\ ${ }^{10}$ Sociedad Mexicana de Cirugía Neurológica, SMCN, Ciudad de Mexico, Mexico $;{ }^{11}$ Centro Médico ABC Campus Santa Fe, Ciudad de Mexico, Mexico; ${ }^{12}$ Department \\ of Neurosurgery Albuquerque, University of New Mexico School of Medicine, USA, Albuquerque, NM; ${ }^{13}$ Desert Institute for Spine Care, Phoenix, AZ, USA
}

\section{ABSTRACT}

Study Design: A design-agnostic standardized effect meta-analysis of 48 randomized, prospective, and retrospective studies on clinical outcomes with spinal endoscopic and interspinous process spacer (IPS) surgery.

Objective: The study aimed to provide reference set of Oswestry Disability Index (ODI) and visual analog scale (VAS) effect size data for back and leg pain following endoscopic and IPS decompression for lumbar herniated disc, foraminal, or lateral recess spinal stenosis.

Background: Mechanical low back pain following endoscopic transforaminal decompression may be more reliably reduced by simultaneous posterior column stabilization with IPS.

Methods: A systematic search of the PubMed, EMBASE, Web of Science, and the Cochrane Central Register of Controlled Trials from 1 January 2000 to 2 April 2020, identified 880 eligible endoscopy and 362 IPS studies varying in design and metrics. The authors compared calculated standardized effect sizes (Cohen's $d$ ) for extracted ODI, VAS-back, and VAS-leg data.

Results: The pooled standardized effect size combining the ODI, VAS-back, and VAS-leg data for the total sample of 19862 data sets from the 30 endoscopy and 18 IPS was 0.877 (95\% CI $=0.857-0.898)$. When stratified by surgery, the combined effect sizes were 0.877 (95\% CI $=0.849-0.905)$ for endoscopic decompression and 0.863 (95\% CI $=0.796-0.930 ; P=0.056$ ) for IPS implantation. The ODI effect sizes calculated on 6462 samples with directly visualized endoscopic decompression were $0.917(95 \% \mathrm{CI}=0.891-0.943)$ versus $0.798(95 \% \mathrm{CI}=0.713-0.883 ; P<0.001)$ with indirect IPS decompression $(P<0.001)$. The VAS-back effect sizes calculated on 3672 samples were 0.661 (95\% CI $=0.585-0.738)$ for endoscopy and 0.784 (95\% CI: 0.644-0.923; $P=0.187)$ for IPS. The VAS-leg effect sizes calculated on 7890 samples were $0.885(95 \% \mathrm{CI}=0.852-0.917)$ for endoscopic decompression and $0.851(95 \% \mathrm{CI}=0.767-0.935 ; P=0.427)$.

Conclusion: Lumbar IPS implantation produces larger reduction in low back pain than spinal endoscopy. On the basis of this meta-analysis, the combination of lumbar transforaminal endoscopy with simultaneous IPS has merits and should be formally investigated in higher grade clinical studies.

Clinical Relevance: Meta-analysis on the added clinical benefit of combining lumbar endoscopic decompression with an interspinous process spacer.

Level of Evidence: 2.

Endoscopic Minimally Invasive Surgery

Keywords: lumbar endoscopy, interspinous process spacer, herniated disc, spinal stenosis, meta-analysis

\section{INTRODUCTION}

Considering stabilization after endoscopic decompression of a severely degenerated lumbar spinal motion segment has been suggested to improve clinical outcomes with this still relatively new outpatient spine surgery. ${ }^{1-3}$ Spinal endoscopy is now increasingly performed for claudication symptoms in the elderly due to herniated disc and spinal stenosis. ${ }^{2,4-10}$ Degenerative disc disease is often associated with progressive loss 
of intervertebral height from vertical collapse, initially causing predominantly foraminal and lateral recess stenosis. ${ }^{11-15}$ In its end stage, degenerative disc disease is known to result in loss of its internal structural integrity, which is often corroborated by the presence of a vacuum phenomenon on radiographic studies. ${ }^{15,16}$ The structural equivalents of such radiographic vacuum discs were recently described as intradiscal fissuring, cavitation, and delamination from the end plate often found during routine inside-out endoscopic direct visualization of the lumbar disc space in over two-thirds of affected patients. ${ }^{17}$ Over time, additional instabilityrelated problems may ensue due to altered facet joint biomechanics, eventually leading to its hypertrophy and hypertrophy of the ligamentum flavum compounding the stenosis problem. ${ }^{3,18,19}$ Overgrowth of the ligamentum flavum has been stipulated to be a direct result of anterolateral instability, ${ }^{20}$ thereby contributing to the late development of central stenosis in addition to foraminal or lateral recess stenosis often seen in the early stages of the disease.

Technological advancements in video endoscopic equipment and instruments afford the contemporary endoscopic spine surgeon the ability to tackle more complex problems, including those seen in patients with severe spinal stenosis. In experienced hands, good longterm outcomes can be achieved with both the insideout $^{21}$ and the outside-in ${ }^{1}$ transforaminal endoscopic decompression. Complication rates, ${ }^{22}$ readmission rates, ${ }^{23}$ reoperation rates, and conversion rates to open fusion surgery are substantially lower with the transforaminal endoscopic decompression surgery-particularly when expertly executed. ${ }^{24}$ While the overall 5-year durability of the transforaminal endoscopic decompression was demonstrated to be excellent without the need for open salvage decompression fusion surgery, ${ }^{1,21,25}$ the additional use of follow-up radiofrequency ablation and endoscopic foraminal decompression procedures may be deemed appropriate in up to one-third of lumbar endoscopy patients to manage contralateral or adjacent segment symptomatic stenosis and mechanical low back pain to maintain the treatment effect of the endoscopic index procedure. ${ }^{1,21,24}$ Effectively, the end result is a staged management approach that we have advocated previously for the treatment of common lumbar pain generators that may affect patients' walking endurance differently depending on the functional context at the time when the spine care is delivered. ${ }^{26}$ Mechanical back pain after endoscopic decompression, particularly in those patients where a hollow vacuum disc is found requiring additional medical, interventional, and surgical treatments, is not uncommon, ${ }^{27-30}$ which is why we entertained the further use of spinal stabilization in conjunction with the lumbar endoscopic spinal surgery. While both anterior ${ }^{31,32}$ and posterior ${ }^{33}$ column stabilization can be considered and are technically feasible to be performed endoscopically, the posterior column stabilization with interspinous process spacers (IPS) appears more attractive because of the (a) ease of minimally invasive implantation ${ }^{34-37}$ and (b) vast extent body of outcome literature on the clinical application of several implant systems in the treatment of claudication symptoms in patients with spinal stenosis, thereby catering to the individual surgeon's preference. ${ }^{38-44}$ Furthermore, nearly all IPS systems are approved by the Food and Drug Administration (FDA) for standalone use obviating the need for posterior supplemental fixation, ${ }^{45-55}$ which would, if necessary, complicate the scope of the endoscopic surgery, raise costs, ${ }^{51,56,57}$ and take away from the attractiveness of the outpatient nature of the endoscopic surgery - a factor that could deter patients specifically seeking out endoscopic spine surgeons who do not subscribe to the routine use of pedicle screws. In contrast, there is currently only one interbody fusion system approved by the FDA for standalone anterior column stabilization. ${ }^{31,58}$ Many other static and expandable interbody fusion systems suitable for the minimally invasive stabilizing anterior column reconstruction are available. ${ }^{58-65}$ Still, they are not FDA approved to be used without supplemental use of posterior pedicle screw instrumentation.

The motivation for the conjunctional use of IPS with the endoscopic spinal decompression procedure stems from the desire to improve clinical outcomes with both methods and their associated durability. It is well known that the endoscopic lumbar decompression may rid patients of sciatica-type low back and leg pain as well as significantly improve endurance-limiting claudication symptoms but leave them with mechanical back pain that can be severe at times. ${ }^{3,66,67}$ IPS are well known to produce good relief from these types of symptoms comparable to the various forms of open and minimally invasive lumbar decompression surgeries in the short term and midterm ${ }^{68-72}$ while being associated with higher long-term reoperation rates than their surgical counterparts involving a formal decompression of the symptomatic compressed neural elements. ${ }^{36,44,73-76}$

In this meta-analysis, comparing numerical clinical outcomes with the directly visualized endoscopic and the nonvisualized indirect IPS decompression, the authors were interested in examining the associated effect sizes (ES) of commonly employed patient-reported outcome 
measures: the Oswestry Disability Index (ODI) ${ }^{77-79}$ and the visual analog scales (VAS) for back and leg pain. ${ }^{80}$ Many published meta-analyses attempted to demonstrate clinical superiority of the endoscopic spinal surgery outcomes when compared to traditional translaminar microsurgical decompression techniques by selecting a few high quality studies, especially randomized controlled trials, ${ }^{81}$ while excluding the findings from noncontrolled studies that are highly prevalent in the spinal surgery literature. Restricting meta-analyses by type of design or, for that matter, metrics of outcomes limits integration of clinically comparable data that might provide a comprehensive view on treatments and associated outcomes across settings.

To the authors' best knowledge, a meta-analysis comparison of results between lumbar endoscopic spinal decompression and IPS implantation that is agnostic to and thus supersedes study design and standardizes observed effects has not been reported. Instead of performing a narrowly focused meta-analysis based on a few randomized prospective, nonrandomized or singlegroup prospective studies, or well-controlled crosssectional retrospective studies, we were interested in a broad investigation of the ES associated with reported clinical outcome improvements with lumbar endoscopic spinal and IPS surgery by extracting and analyzing the ODI and VAS means, SD, and the number of patients in each study. We performed additional subcategory, modifier, and wave analyses to cross-tabulate extracted ES by the length of follow-up, patients' age, the indication for surgery, the publication year, and the type of study design employed by the authors of the original studies. Ultimately, the authors intended to create a reference table of ES with the IPS and endoscopic spinal surgery to employ it in the comparative evaluation of the clinical merits of combing these 2 procedures.

\section{MATERIALS AND METHODS}

\section{Search Strategy and Study Selection}

The authors were interested in analyzing the ES data reported for commonly used numerical clinical outcome instruments including the ODI, ${ }^{77-79}$ and $\mathrm{VAS}^{80}$ for back and leg pain with lumbar endoscopic decompression and the IPS procedures. Therefore, we performed a meta-analysis of clinical studies on IPS and endoscopic decompression for lumbar herniated disc and spinal stenosis, reported here in alignment with the Preferred Reporting Items for Systematic Reviews and MetaAnalyses guidelines. ${ }^{82-89}$ For this purpose, 3 authors (KUL, MYW, and ATY) searched the English-language literature on PubMed, Embase, Web of Science, and the Cochrane Database from 1 January 2000 to 31 December 2019 using "lumbar" and "herniated disc" or "spinal stenosis" and "endoscopic" and "ODI" and "VAS," or "interspinous" and "process" and "spacer" as keywords. They compared their searches to finalize the set of studies to be reviewed for possible inclusion. Discrepancies were resolved by consensus (Figure 1).

\section{Inclusion/Exclusion Criteria and Data Extraction}

To be retained in the meta-analysis, studies needed to employ cross-sectional retrospective, prospective single treatment group, or randomized prospective multitreatment arm study designs comparing endoscopic with other minimally invasive spinal surgery techniques (MISST) including tubular retractor, and others. Studies needed to report IPS and endoscopic spinal surgery outcomes on patients suffering from symptoms related to lumbar herniated disc and foraminal or lateral recess stenosis utilizing the ODI, and the respective VAS scales for back and leg pain. IPS studies using the Zürich claudication score ${ }^{90-93}$ were excluded since it is not a common outcome measurement tool in endoscopic spinal surgery studies. Only studies that reported the mean, the SD, and the sample size preoperatively and postoperatively for the ODI, VAS-back, and VAS-leg were retained as this was essential information to calculate the effect metrics. Retrieved studies were further stratified by the type of endoscopic MISST access to the neural elements including transforaminal, interlaminar, or combinations, or variations of these techniques. Case reports, review articles, letters to the editor, editorials, short-term reports, and nonclinical studies, such as biomechanical and cadaveric studies, were excluded.

\section{Statistical Analysis}

\section{Database}

We compiled a database of the included studies by recording the first study author and up to 2 additional coauthors (to differentiate between papers with same and similarly named first author), year of publication, study patients' mean age, and the preoperative baseline and the postoperative numerical ODI, VAS-back, and VAS-leg scores at final available follow-up. Studies comparing multiple treatments were categorized by comparisons of "endoscopy" or "IPS" implantation vs "microsurgical" or "open" decompression. Additional moderators used in the analysis were study design (retrospective, prospective, and randomized prospective), indication for surgery (herniated disc 


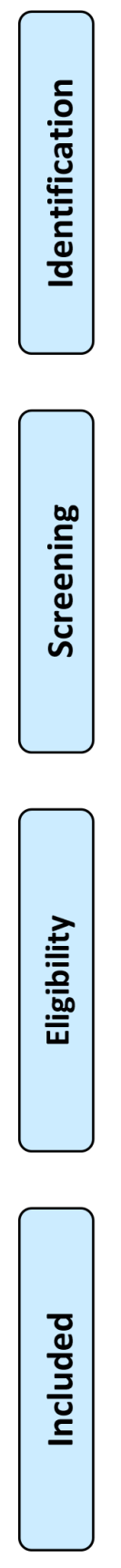

Pubmed \& Embase Web of Science, and Cochrane search "lumbar", "herniated disc", or "spinal stenosis", "endoscopic", "ODI", "VAS" 01/01/2000 to 12/31/2019 ( $n=880$ articles)
Pubmed \& Embase Web of Science, and Cochrane additional search "interspinous", "process", "spacer", "ODI", "VAS", 01/01/2000 to $12 / 31 / 2019$ ( $n=362$ articles)

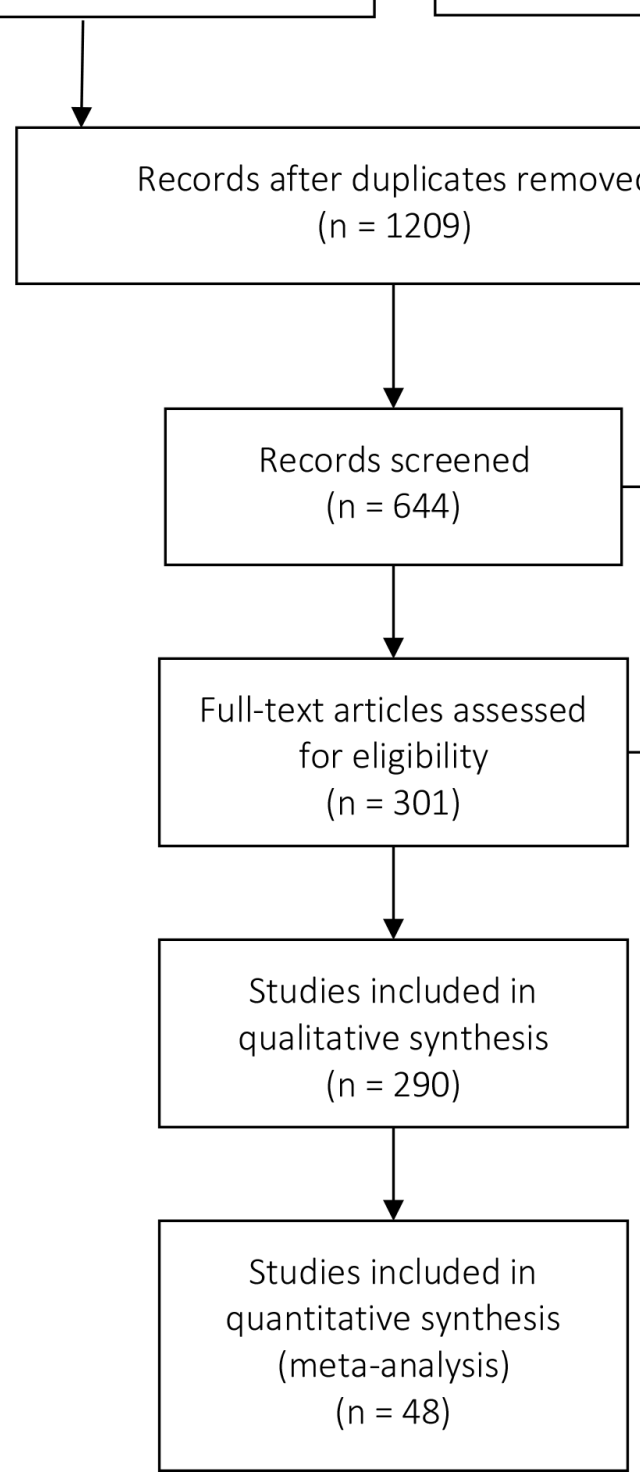

Figure 1. The Preferred Reporting Items for Systematic Reviews and Meta-Analyses flowchart of selected endoscopy and interspinous process spacer studies. ODI, Oswestry Disability Index; VAS, visual analog scale.

radiculopathy, stenosis claudication, and discogenic pain), type of MISST (endoscopy, open laminectomy, or tubular microdiscectomy), and IPS implantation.

\section{Standardization of Effects Across Study Designs}

Clinical outcome data extracted from the articles included in this meta-analysis were the means and SDs of the VAS-back, the VAS-leg, and the ODI, as well as the sample sizes preoperatively and postoperatively. The ES of postoperative improvements relative to preoperative status was calculated on the basis of the number of enrolled study patients available at last follow-up using Cohen $d$ :

$$
d=\left(M_{\text {postop }}-M_{\text {preop }}\right) / \mathrm{SD}_{\text {pooled }}
$$

where $M$ refers to the respective preoperative and postoperative means and $\mathrm{SD}_{\text {pooled }}$ to the pooled $\mathrm{SD}$ of the preoperative and postoperative scores on the 3 scales of interest. ${ }^{94,95}$ By convention, $d=0.2$ is considered a "small" ES, $d=0.5$ represents a "medium" ES, and $d$ 
$=0.8$ a "large" ES. We applied $d=0.2$ as the threshold, meaning that if the means of outcomes in endoscopy and IPS did not differ at a minimum by 0.2 SDs, the difference was considered trivial even if statistically significant.

\section{Analysis}

The calculated ES, lower limit, upper limit, Higgins $I^{2}$ statistic of heterogeneity $\left(I^{2}\right)$, variance $(V)$, SE, number of patients, and significance level (sig) of 95\% CI were tabulated for all outcomes combined (ODI, VAS-back, and VAS-leg) and for each outcome separately; this was done across both surgery types and stratified by each surgery. Significance testing for differences between types of surgery was done using random effects analysis of variance of the studentized range statistic $Q$ with separate estimates of $T^{2}$ used in the between-group sum-of-squares estimation. These procedures were also applied to subanalyses by study design (retrospective, prospective, and randomized prospective) and surgery indication (herniated nucleus pulposus [HNP]; stenosis claudication). The average reduction of ODI, VAS-back, and VAS-leg was compared to the reported and calculated minimal clinically important difference parameters of 3.0 for the VAS-back and VAS-leg and 15 for ODI. ${ }^{96-101}$ Statistical significance was set at $\alpha$ of 0.05 .

Each of the ODI, VAS-back, and VAS-leg means of each study was weighted in inverse proportion of the respective variances and thus proportional to its precision. Heterogeneity among studies on an outcome of interest was examined by the Cochran $Q$ test with the Higgins $I^{2}$ statistic quantifying the percentage of variation across studies due to heterogeneity rather than chance. However, as patient-reported outcomes such as the ODI and, especially, the 2 VAS scales are known to be ordinal and inherently anchorless due to interindividual variation in thresholds and valuation, we considered the $I^{2}$ as informative but not as cutoffs. To further offset this, all analyses applied a random effects model. Weighted metaregression plots were generated to evaluate associations between standardized ES and the potential moderator variables of patient age (in years) and follow-up (in months). Funnel plots (SE vs ES) were visually assessed for evidence of publication bias and by calculating the one-sided $P$ value for intercept in Egger linear regression analysis and Kendall's $\tau$. Analyses were performed using Prometa 3, version 3.0 (Internovi, Borne, The Netherlands, 2015). Prometa 3 plotted the ES data in terms of non-standardized differences.

\section{RESULTS}

\section{Search Results}

The first search yielded 880 publications, and the second search identified another 362 publications. Applying the inclusion/exclusion criteria, 48 publications were subjected to a full-text review resulting in the inclusion of 29 endoscopy ${ }^{5,7,30,102-127}$ and 19 IPS studies in this meta-analysis (Figure 1). ${ }^{42,46,53,70,128-142}$

\section{Meta-Analysis Results for Clinical Outcomes}

The pooled standardized ES when combining the ODI, VAS-back, and VAS-leg data for the total sample size of 19,862 data sets from the 30 endoscopy studies and 18 interspinous spacer (ISP) studies revealed an overall ES of 0.877 (95\% CI = 0.857-0.898). Stratifying by type of surgery, the pooled standardized ES across all outcomes were $0.877(95 \% \mathrm{CI}=0.849-0.905 ; N=$ 10230) for endoscopic decompression and $0.863(95 \%$ $\mathrm{CI}=0.796-0.930 ; N=8508$ ) for IPS implantation, with the difference marginally failing statistical significance $(P=0.056)$.

In analyses by specific outcome, the pooled standardized ES for ODI $(N=6462)$ were $0.916(95 \%$ $\mathrm{CI}=0.891-0.943 ; N=4364)$ for lumbar endoscopic decompression and 0.798 (95\% CI $=0.713-0.883 ; N$ $=2098)$ for the IPS procedures-a difference that was statistically significant $(P=0.001)$ (Figure 2; Table 1). The pooled standardized ES for VAS-back $(N=3672)$ were $0.661(95 \% \mathrm{CI}=0.585-0.738 ; N=1574)$ for lumbar endoscopic decompression and 0.784 (95\% CI $=0.644-0.923 ; N=2098$ ) for the IPS procedures- $\mathrm{a}$ difference that was not statistically significant $(P=$ 0.187 ) (Figure 3; Table 1). The pooled standardized ES for VAS-leg $(N=7890)$ were $0.885(95 \% \mathrm{CI}=0.852$ $0.917 ; N=4292$ ) for lumbar endoscopic decompression and 0.851 (95\% CI $=0.767-0.935 ; N=3598$ ) for the IPS procedures-a difference that was not statistically significant $(P=0.427)$ (Figure 4; Table 1).

Weighted regression analysis showed no significant $(P=0.289)$ association between pooled standardized ES and patient age (Figure 5); but did reveal an overall significant association $(P=0.026)$ between pooled standardized ES and follow-up (in months; Figure 6). Visual inspection of Figure 6 shows a large cluster of studies with follow-up of 24 months and many studies with longer follow-up compared to much fewer studies with follow-up less than 24 months. Further analysis revealed that follow-up of 24 months or more occurred in all of the ISP studies. 


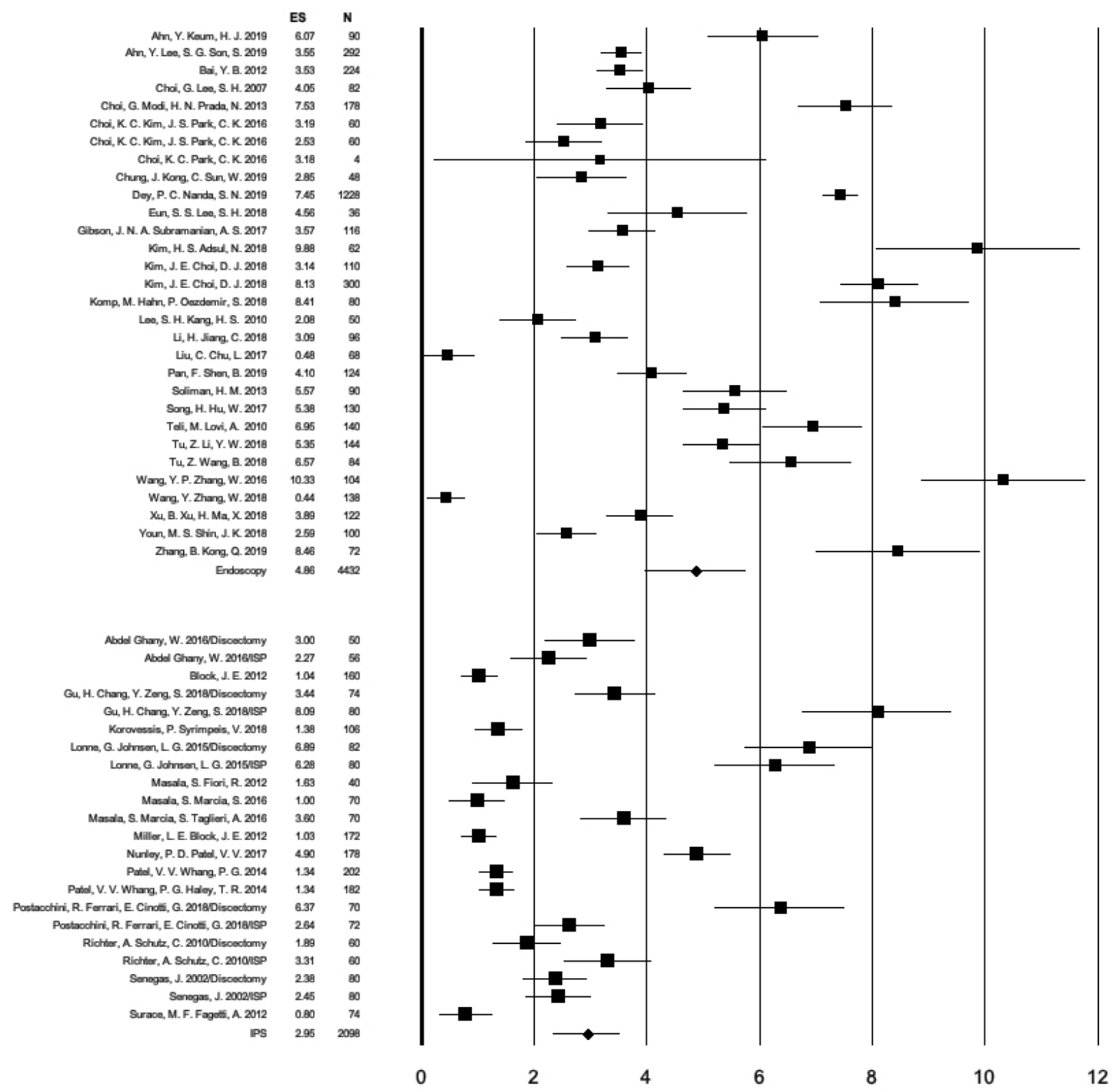

Figure 2. Forest plot of calculated Oswestry Disability Index (ODI) effect sizes (ES), 95\% Cl, and the number of patients enrolled in each of the endoscopic spinal surgery and interspinous process spacer (IPS) studies listed in alphabetical order according to the first author's name. The number of individual study patients is represented by the size of the square. The calculated pooled standardized ES for changes in ODI for the endoscopy studies was 0.917 ( $95 \% \mathrm{Cl}=0.891-0.943$ ). The corresponding ES for the IPS procedures was $0.798(95 \% \mathrm{CI}=0.713-0.883)$. The analysis of variance $Q$ test of difference showed a statistically higher ODI ES with endoscopy than with the IPS procedure $(P=0.001)$. Prometa 3 plotted the ES data in terms of non-standardized differences.

Egger's regression yielded an intercept of $5.93(P=$ $0.001)$, and Kendall's $\tau$ was $-2.17(P=0.030)$ in analyses including all 3 outcome variables. The asymmetric funnel plot with several studies falling outside the expected area of SE vs ES further indicates moderate publication bias (Figure 7).

\section{Meta-Analysis by Modifiers}

Subanalyses by study design (Table 2 ) revealed pooled standardized ES for the ODI $(N=6462)$ of $0.884(95 \%$ $\mathrm{CI}=0.846-0.922 ; N=3314)$ for retrospective studies,
$0.890(95 \% \mathrm{CI}=0.821-0.960 ; N=1774)$ for prospective studies, and $0.843(95 \% \mathrm{CI}=0.729-0.957 ; N=$ 1374) for randomized prospective studies (differences not significant, $P=0.742$ ). Pooled standardized ES for the VAS-back $(N=4386)$ were $0.715(95 \% \mathrm{CI}=0.587-$ $0.843 ; N=2560)$ for retrospective studies, $0.425(95 \%$ $\mathrm{CI}=0.048-0.803 ; N=284$ ) for prospective studies, and $0.806(95 \% \mathrm{CI}=0.653-0.959 ; N=1542)$ for randomized prospective studies (differences not significant, $P$ $=0.112)$. Pooled standardized ES for the VAS-leg $(N=$ $7890)$ were $0.866(95 \% \mathrm{CI}=0.819-0.912 ; N=4716)$ 
Lewandrowski et al.

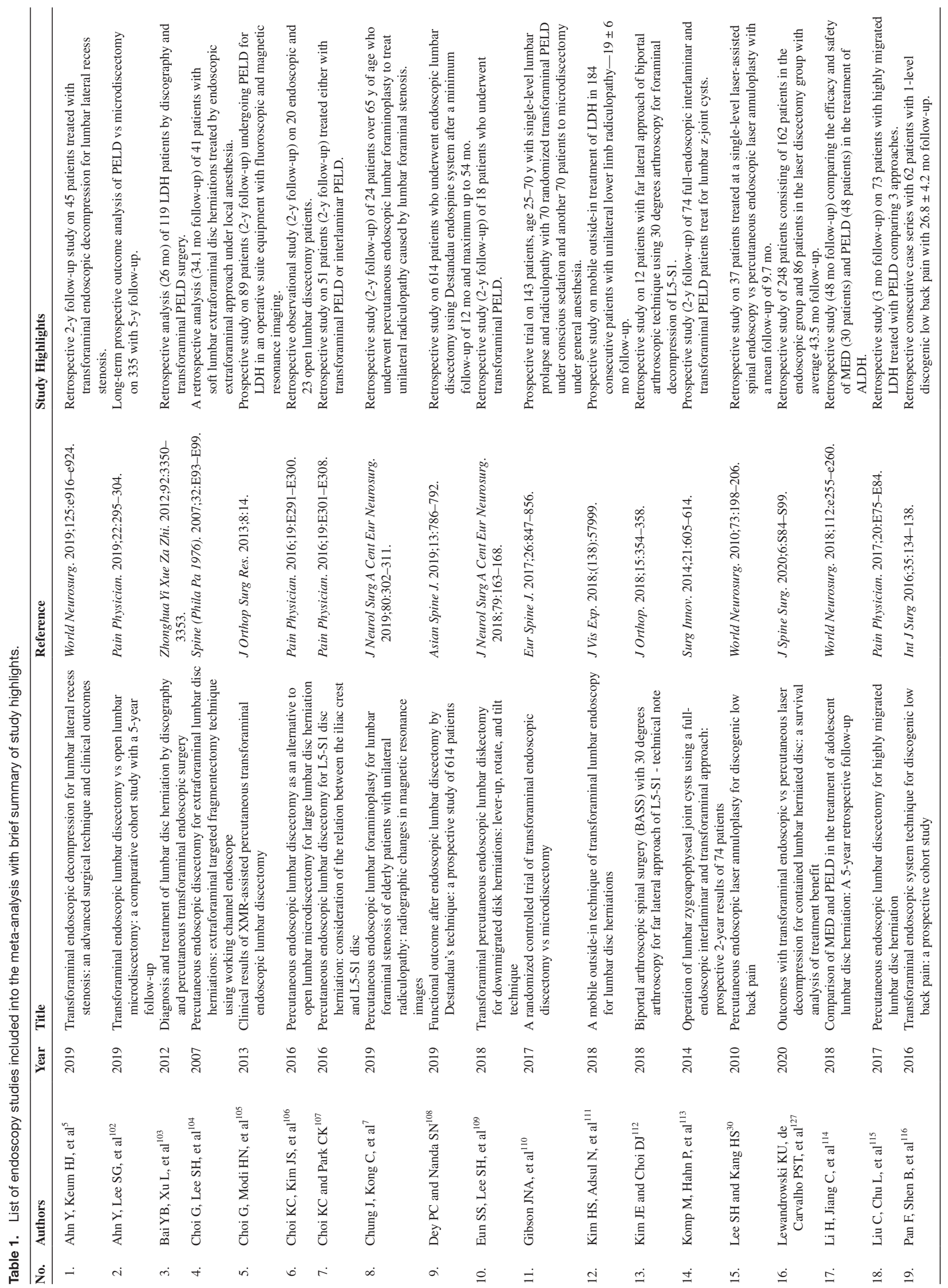


Full Lumbar Endoscopy vs Interspinous Process Spacers for Spinal Stenosis

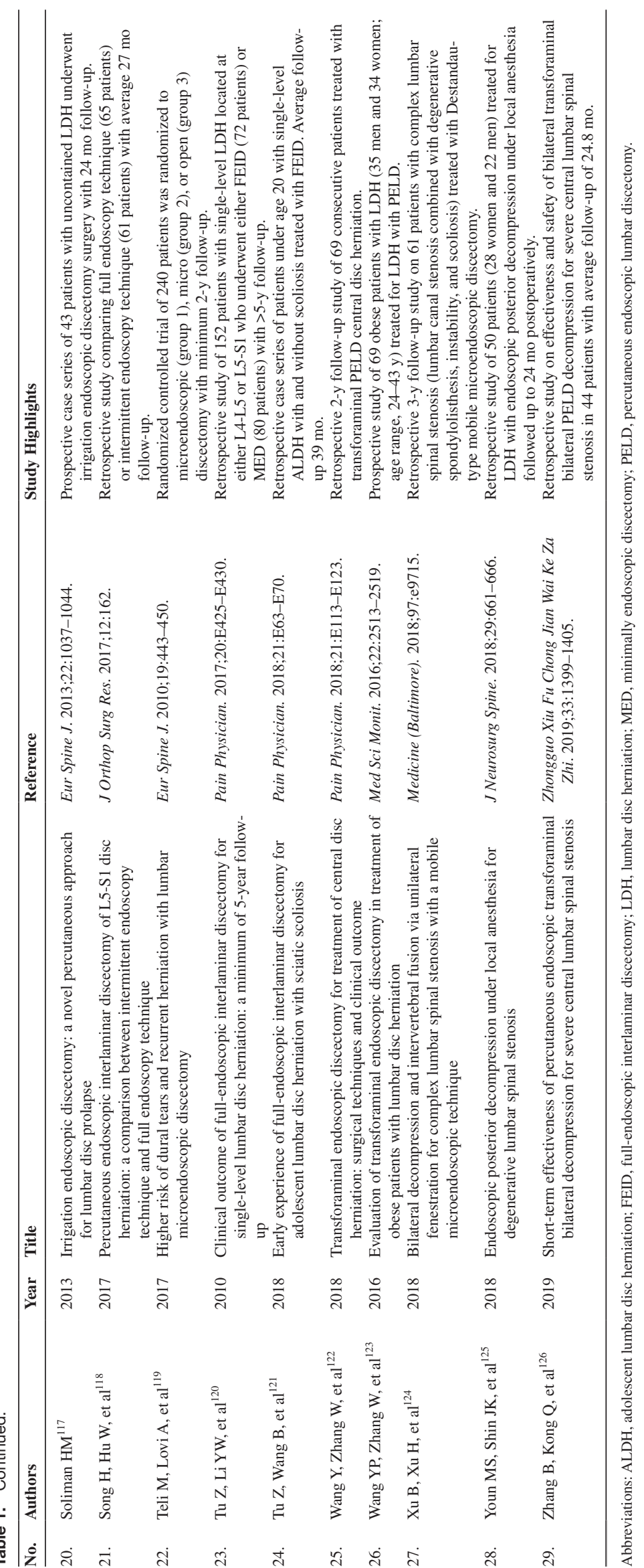




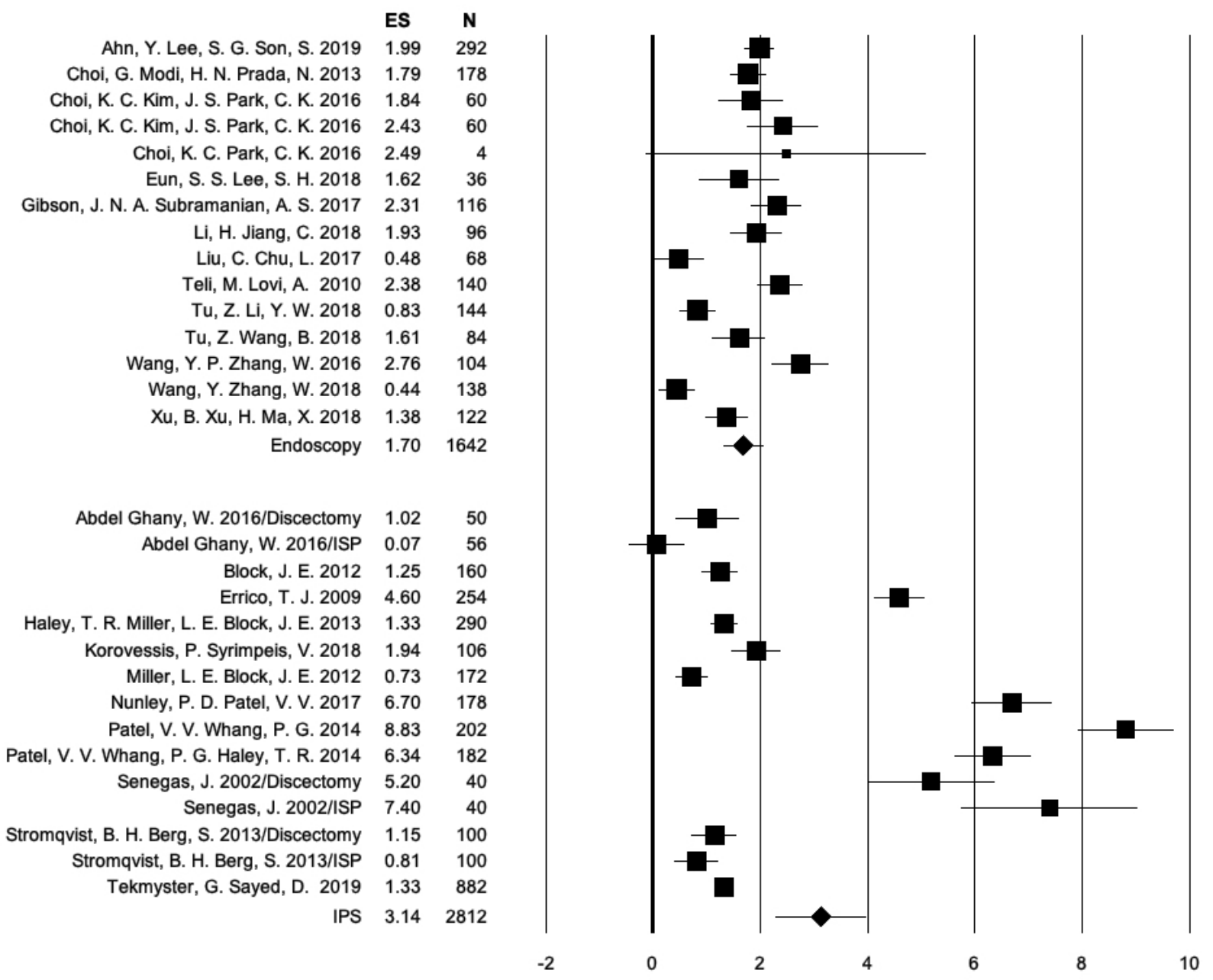

Figure 3. Forest plot of calculated visual analog scale (VAS)-back effect sizes (ES), 95\% Cl, and the number of patients enrolled in each of the endoscopic spinal surgery and interspinous process spacer (IPS) studies listed in alphabetical order according to the first author's name. The number of individual study patients is represented by the size of the square. The calculated pooled standardized ES for changes in VAS-back for the endoscopy studies was 0.661 (95\% $\mathrm{Cl}=0.585-$ 0.738). The corresponding ES for the IPS procedures was $0.784(95 \% \mathrm{Cl}=0.644-0.923)$. The analysis of variance $Q$ test of difference indicated that this difference in VAS-back ES was not statistically significant $(P=0.187)$. Prometa 3 plotted the ES data in terms of non-standardized differences.

for retrospective studies, $0.912(95 \% \mathrm{CI}=0.885-0.938$; $N=1632)$ for prospective studies, and $0.860(95 \% \mathrm{CI}$ $=0.733-0.987 ; N=1542$ ) for randomized prospective studies (differences not significant, $P=0.175$ ).

Subanalyses by surgery indication (Table 3 ) yielded pooled standardized ES for the ODI $(N=2884)$ of 0.920 (95\% CI $=0.862-0.977 ; N=880$ ) for HNP radiculopathy and $0.815(95 \% \mathrm{CI}=0.722-0.907 ; N=2004)$ for stenosis claudication (differences not significant, $P=$ 0.076). Pooled standardized ES for the VAS-back $(N=$ $3286)$ were $0.532(95 \% \mathrm{CI}=0.271-0.794 ; N=506)$ for HNP radiculopathy and 0.694 (95\% CI $=0.514$ 0.874; $N=2780$ ) for stenosis claudication (differences not significant, $P=0.307)$. Pooled standardized ES for the VAS-leg $(N=4464)$ were $0.868(95 \% \mathrm{CI}=0.769$ $0.966 ; N=880)$ for HNP radiculopathy and $0.830(95 \%$ $\mathrm{CI}=0.736-0.874 ; N=3584$ ) for stenosis claudication (differences not significant, $P=0.869$ ).

\section{Individual Studies Results and Minimal Clinically Important Difference}

Preoperative baseline means (SD) were 59.34 (SD 12.67) for the ODI, 4.90 (SD 1.89) for the VAS-back, and 7.22 for the VAS-leg (SD 1.90). Improvements after endoscopic surgery were an ODI reduction of 46.25 (SD 6.10), VAS-back reduction of 3.29 (SD 0.65), and VASleg reduction of 5.77 (SD 0.66). The mean (SD) percent changes of ODI, VAS-back, and VAS-leg ratings at a follow-up of 2 years or longer after endoscopic decompression were $77.94 \%$ (SD $10.28 \%$ ), $67.14 \%$ (SD $13.26 \%$ ), and $79.71 \%$ (SD 9.14\%), respectively. The mean (SD) percent change of ODI, VAS-back, and VAS-leg at a follow-up of 2 years or longer after ISP implantation was 68.31\% (SD 9.39\%), 58.12\% (SD $11.51 \%$ ), and $71.21 \%$ (SD $11.26 \%$ ), respectively. The ODI, VAS-back, and VAS-leg reductions producing the 


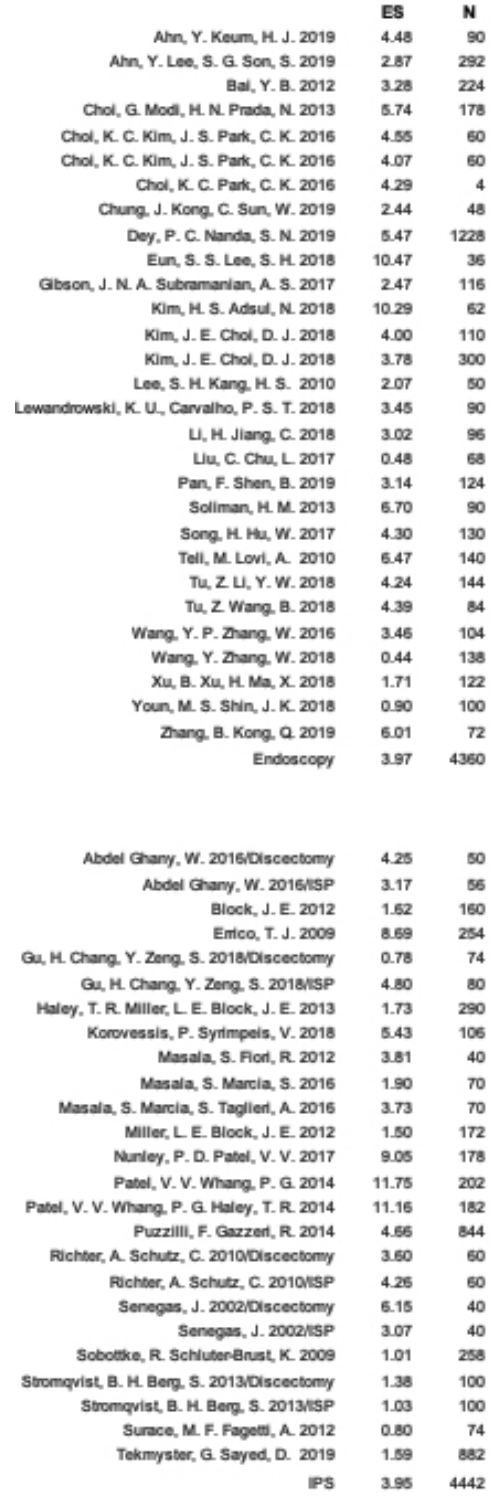

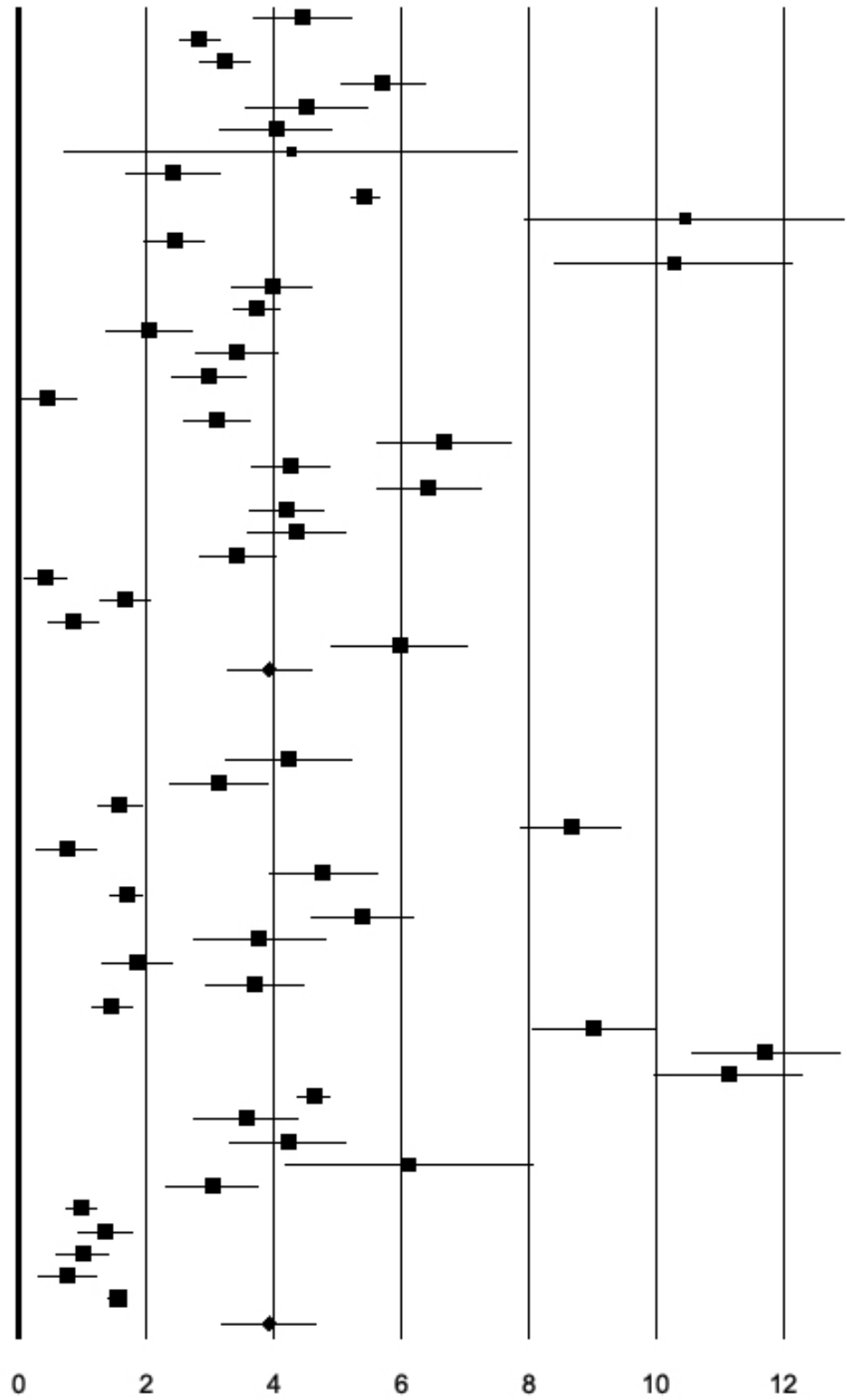

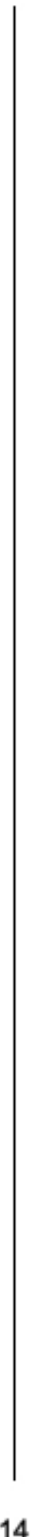

Figure 4. Forest plot of calculated visual analog scale (VAS)-leg effect sizes (ES), 95\% CI, and the number of patients enrolled in each of the endoscopic spinal surgery and interspinous process spacer (IPS) studies listed in alphabetical order according to the first author's name. The number of individual study patients is represented by the size of the square. The calculated pooled standardized ES for changes in VAS-leg for the endoscopy studies was 0.885 (95\% $\mathrm{Cl}=0.852-0.917$ ). The corresponding ES for the IPS procedures was $0.851(95 \% \mathrm{Cl}=0.767-0.935)$. The analysis of variance $Q$ test of difference indicated that this difference in VASleg ES was not statistically significant $(P=0.427)$.

ES calculations listed in Tables $1-3$ were the equivalent of 3 times reported minimal clinically important differences. $^{84}$

\section{DISCUSSION}

One might ask, what is the point of combining lumbar spinal endoscopy with the placement of an IPS? To those who routinely perform both types of surgeries, the answer is quite obvious. Both procedures have shortcomings that are far outweighed by their advantages but in some cases prompt new interventional and surgical management following the index procedure. In short, spinal endoscopy is attractive to many patients because of the small incisions, low complication rates, ${ }^{22,23}$ and its outpatient nature. The staged management approach to common lumbar spinal pain generators the authors advocate for ${ }^{143}$ translates into minor concise surgeries on validated pain generators, while ignoring many other structural problems not contributing to the patient's pain syndrome in the current context of spine care at the time when the care is delivered. Endoscopy's downside is persistent mechanical low back pain, which in 


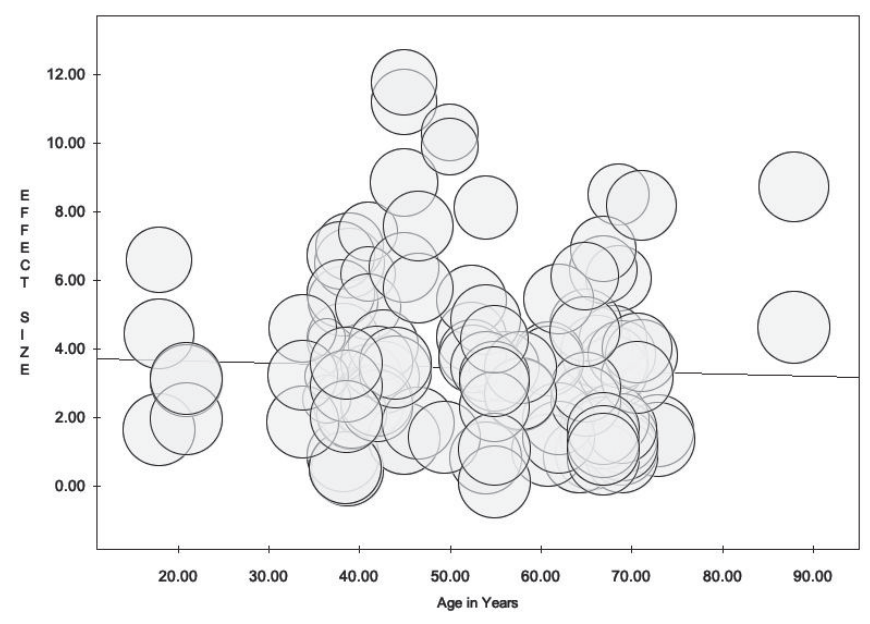

Figure 5. Meta-analysis regression plot of effect size vs age in years using random effects model showed no significant correlation $(P=0.289)$.

many patients stems from facet arthropathy or severely degenerated vacuum discs. IPS implants, on the other hand, are attractive because of the simplicity of implantation and the low perioperative burden to spinal stenosis patients who often suffer from poorly controlled medical comorbidities. ${ }^{76}$ The short-term and midterm track record of IPS to improve claudication symptoms is favorable, ${ }^{41,44,48,53,56,68-70,128,129,144-148}$ but the reoperation rate is higher than with formal open lumbar decompression surgery. ${ }^{44,48,52,53,55,74,75,128,139,146,148-154}$ IPS procedures also have been demonstrated to relieve mechanical back pain effectively. ${ }^{71}$ Hence, combining lumbar spinal endoscopy and IPS procedures may ultimately improve clinical outcomes with these 2 nonfusion technologies - a strategy that fits well within the scope of cost-saving policies of modern healthcare systems. This dynamic was the underlying motivation

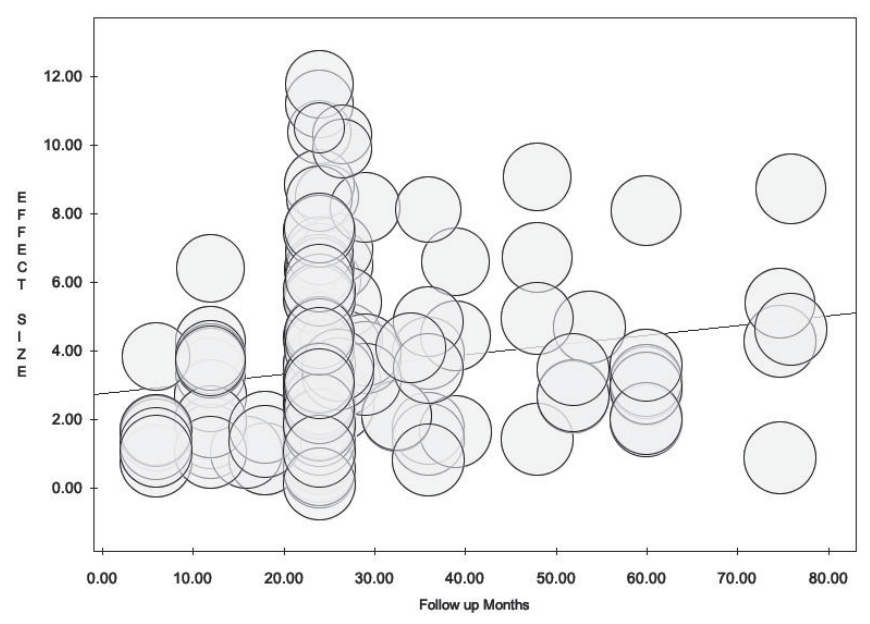

Figure 6. Meta-analysis plot of effect size (ES) vs follow-up in months using random effects model showed a statistically significantly higher proportion of studies (all of the interspinous spacer studies) with either 24 months follow-up or more with higher ES numbers in the longer follow-up studies $(P=0.026)$.

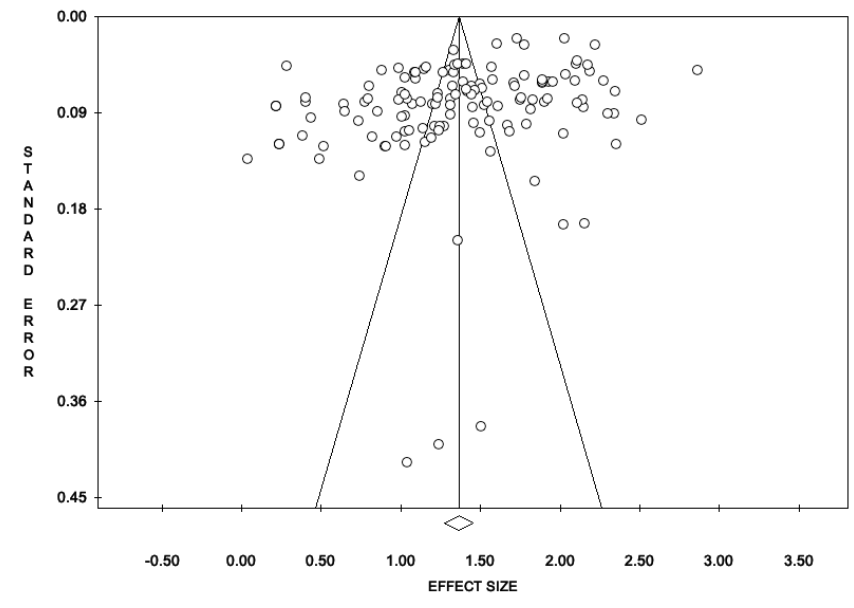

Figure 7. Funnel plot assessing publication bias (SE vs effect size).

of this meta-analysis, which accompanies an original study and review article that is published alongside this meta-analysis in this special focus issue of the International Journal of Spine Surgery.

We took a broad approach to extract outcome data from original studies on endoscopic and IPS spinal surgeries to afford the reader the ability to better compare their clinical benefit concerning indication for surgery and burden to the patient in an across-the-board normalized comparison. Highlighting differences in outcomes between directly visualized endoscopic and the indirect IPS decompression by reporting the standardized ES has several advantages, including the ability to test report statistical tests for group comparison. Standardized ES quantify the gradient of difference between the treatment groups rather than confounding this difference with sample size and statistical power. ${ }^{155-157}$ As eq. 1 above shows, $d$ is calculated by subtracting the mean of one group from the mean of another group and dividing it by the pooled SD. Despite being standardized and simple, the ES is rarely used in the comparison and discussion of clinical outcomes between treatments. ${ }^{155}$ As we showed here, the $d$ metric can be highly useful as a measure of overlap of treatment benefit between spinal endoscopic and IPS procedures-a form of data interpretation we employed in this study to illustrate the various aspects of clinical benefit between the types of lumbar decompression procedures.

We chose the meta-analysis approach to calculating ES since it overcomes the common problem of not knowing the SD of the population from which the different treatment groups were sampled by estimating it by pooling data from the treatment groups of various studies. The ES derived from preoperative and postoperative disability data (ODI, VAS-back, and VAS-leg) 


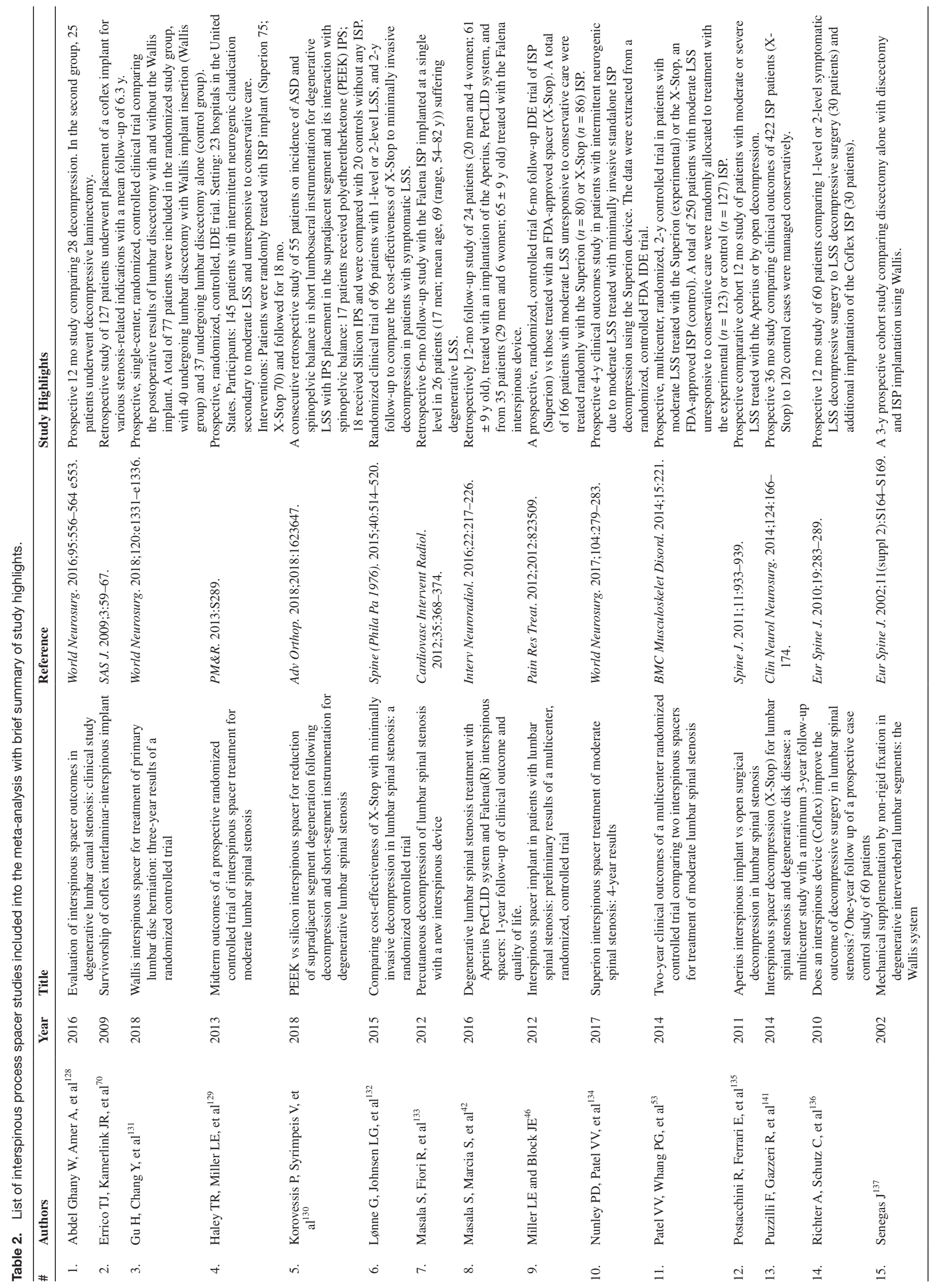


Lewandrowski et al.

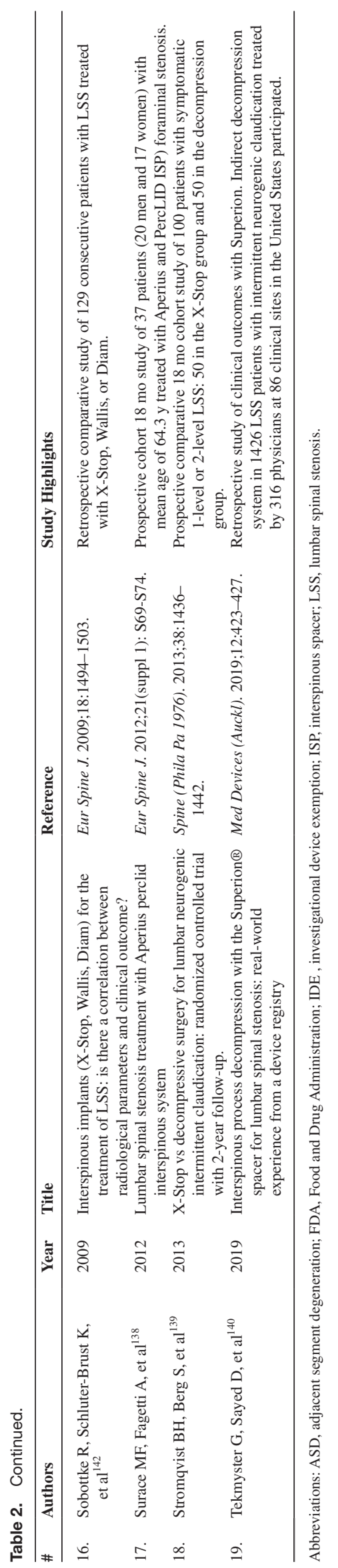

Downloaded from http://ijssurgery.com/ by guest on April 26, 2023

International Journal of Spine Surgery, Vol. 00, No. 00 
Table 3. Analysis of effect size, heterogeneity, and ANOVA testing of difference by surgery type.

\begin{tabular}{|c|c|c|c|c|c|c|c|c|c|}
\hline $\begin{array}{l}\text { Outcome } \\
\text { Measure }\end{array}$ & Type of Surgery & $\begin{array}{l}\text { Number of Studies } \\
\text { Included in This } \\
\text { Analysis (Multiple } \\
\text { Study Groups } \\
\text { Possible) }\end{array}$ & Effect Sizes & Lower Limit & Upper Limit & $\begin{array}{l}\text { Higgins } I^{2} \text { Statistic } \\
\text { of Heterogeneity }\end{array}$ & Variance & SE & $N$ \\
\hline Oswestry & Endoscopy & 29 & 0.912 & 0.891 & 0.943 & $0 \%$ & 0.0002 & 0.0132 & 4364 \\
\hline \multirow[t]{2}{*}{ Index } & \multirow{2}{*}{\multicolumn{4}{|c|}{$\begin{array}{l}\text { spacer } \\
\text { ANOVA } Q \text { random effects test with separate estimates of } T^{2}\end{array}$}} & 0.883 & $0 \%$ & 0.0019 & 0.0435 & 2098 \\
\hline & & & & & \multicolumn{2}{|c|}{$P=0.001$} & \multicolumn{2}{|c|}{ Total $N$ patients } & 6462 \\
\hline \multirow{3}{*}{ VAS-back } & Endoscopy & 14 & 0.661 & 0.585 & 0.734 & $0 \%$ & 0.0015 & 0.0389 & 1574 \\
\hline & $\begin{array}{l}\text { Interspinous process } \\
\text { spacer }\end{array}$ & 15 & 0.784 & 0.644 & 0.923 & $0 \%$ & 0.0050 & 0.0711 & 2098 \\
\hline & \multicolumn{4}{|c|}{ ANOVA $O$ random effects test with separate estimates of $T^{2}$} & \multicolumn{2}{|c|}{$P=0.187$} & \multicolumn{2}{|c|}{ Total $N$ patients } & 3672 \\
\hline \multirow[t]{3}{*}{ VAS-leg } & Endoscopy & 28 & 0.885 & 0.852 & 0.917 & $0 \%$ & 0.000 & 0.017 & 4292 \\
\hline & $\begin{array}{l}\text { Interspinous process } \\
\text { spacer }\end{array}$ & 24 & 0.851 & 0.767 & 0.935 & $0 \%$ & 0.002 & 0.043 & 3598 \\
\hline & \multicolumn{6}{|c|}{ ANOVA $Q$ random effects test with separate estimates of $T^{2}$} & \multicolumn{2}{|c|}{ Total $N$ patients } & 7890 \\
\hline
\end{tabular}

Abbreviations: ANOVA, analysis of variance; VAS, visual analog scale.

from a total of 48 studies were, in general, large. ${ }^{95}$ Importantly, they tended to exceed established reference data set of ES with the endoscopic and the IPS procedures by a multiple of about 3 , which to the authors' best knowledge has not been published.

Despite the majority of patients treated with endoscopic or IPS surgery were between the ages of 40 and 70 years, patient age was not found to impact clinical outcomes (Figure 5). Further, and important given the general challenge in surgery for randomized (blinded) clinical trials, neither did the type of study design impact ES - though with one, albeit positive, exception: the ES calculated for the VAS-back underscored the long-term ( 2 years or more postsurgery) benefit of IPS in relief of back pain (Figure 6), especially in higher quality randomized prospective trials with therefore lower risk of bias. When stratifying by surgical indication as a modifier, ODI and VAS-leg ES for the surgery indication of spinal stenosis-related neurogenic claudication were similar and both were higher than the corresponding ES for VAS-back (Table 4). The overlap in the precision (95\% CI) estimates between the VAS-leg ES for the 2 clinical indications studied-stenosis claudication and HNP radiculopathy - was quite large, suggesting that both endoscopic and IPS spinal surgery are effective in relieving symptoms due to either one of these 2 conditions. The calculated VAS-back ES were the higher for the IPS than for endoscopy but not statistically significant because of a large 95\% CI overlap. Therefore, the authors' clinical observation that IPS implantation produces more back pain reduction than endoscopy will need to be formally studied in high quality controlled clinical trials to substantiate this conclusion. Our metaanalysis did not directly compare the clinical 2 outcomes. It instead identified the predominant clinical improvement areas-better improvement of low back pain symptoms with IPS and better radicular pain relief with directly visualized endoscopic decompression. These observations are corroborated by 2 retrospective clinical cohort studies that evaluated clinical outcomes in patients who underwent combined transforaminal endoscopic decompression with simultaneous placement of an IPS. ${ }^{33,158}$ Another 2-year follow-up study performed by this team of authors on simultaneous

Table 4. Analysis of effect size, heterogeneity, and ANOVA testing of difference by surgery indication.

\begin{tabular}{|c|c|c|c|c|c|c|c|c|c|}
\hline Outcome Measure & $\begin{array}{l}\text { Indication for } \\
\text { Surgery }\end{array}$ & $\begin{array}{c}\text { Number } \\
\text { of Studies } \\
\text { Included in } \\
\text { This Analysis } \\
\text { (Multiple } \\
\text { Study Groups } \\
\text { Possible) }\end{array}$ & Effect Size & Lower Limit & $\begin{array}{l}\text { Upper } \\
\text { Limit }\end{array}$ & $\begin{array}{c}\text { Higgins } I^{2} \text { Statistic } \\
\text { of Heterogeneity }\end{array}$ & Variance & SE & $N$ \\
\hline \multirow{3}{*}{$\begin{array}{l}\text { Oswestry Disability } \\
\text { Index }\end{array}$} & HNP radiculopathy & 8 & 0.920 & 0.862 & 0.977 & $0 \%$ & 0.0009 & 0.0295 & 880 \\
\hline & Stenosis claudication & 21 & 0.815 & 0.722 & 0.907 & $0 \%$ & 0.0022 & 0.0472 & 2004 \\
\hline & \multicolumn{4}{|c|}{ ANOVA $Q$ random effects test with separate estimates of $T^{2}$} & \multicolumn{2}{|r|}{$P=0.076$} & \multicolumn{2}{|c|}{ Total $N$ patients } & 2884 \\
\hline \multirow[t]{3}{*}{ VAS-back } & HNP radiculopathy & 4 & 0.532 & 0.271 & 0.794 & $<1 \%$ & 0.0178 & 0.1333 & 506 \\
\hline & Stenosis claudication & 14 & 0.694 & 0.514 & 0.874 & $0 \%$ & 0.0084 & 0.0919 & 2780 \\
\hline & \multicolumn{4}{|c|}{ ANOVA $Q$ random effects test with separate estimates of $T^{2}$} & \multicolumn{2}{|r|}{$P=0.307$} & \multicolumn{2}{|c|}{ Total $N$ patients } & 3286 \\
\hline \multirow[t]{3}{*}{ VAS-leg } & HNP radiculopathy & 8 & 0.868 & 0.769 & 0.966 & $0 \%$ & 0.0025 & 0.0503 & 880 \\
\hline & Stenosis claudication & 23 & 0.830 & 0.736 & 0.924 & $0 \%$ & 0.0023 & 0.0480 & 3584 \\
\hline & \multicolumn{4}{|c|}{ ANOVA $Q$ random effects test with separate estimates of $T^{2}$} & \multicolumn{2}{|r|}{$P=0.869$} & \multicolumn{2}{|c|}{ Total $N$ patients } & 4464 \\
\hline
\end{tabular}

Abbreviations: ANOVA, analysis of variance; HNP, herniated nucleus pulposus; VAS, visual analog scale. 
Table 5. Analysis of effect size, heterogeneity, and ANOVA testing of difference by study type.

\begin{tabular}{|c|c|c|c|c|c|c|c|c|c|}
\hline $\begin{array}{l}\text { Outcome } \\
\text { Measure }\end{array}$ & Study Design & $\begin{array}{l}\text { Number of Studies } \\
\text { Included in This } \\
\text { Analysis (Multiple } \\
\text { Study Groups } \\
\text { Possible) }\end{array}$ & Effect Size & $\begin{array}{c}\text { Lower } \\
\text { Limit }\end{array}$ & $\begin{array}{l}\text { Upper } \\
\text { Limit }\end{array}$ & $\begin{array}{c}\text { Higgins } I^{2} \text { Statistic } \\
\text { of Heterogeneity }\end{array}$ & Variance & SE & $N$ \\
\hline Oswestry & Prospective study & 8 & 0.890 & 0.821 & 0.960 & $0 \%$ & 0.0013 & 0.0354 & 1774 \\
\hline Disability & Randomized prospective study & 11 & 0.843 & 0.729 & 0.957 & $0 \%$ & 0.0034 & 0.0581 & 1374 \\
\hline \multirow[t]{2}{*}{ Index } & Retrospective study & 32 & 0.884 & 0.846 & 0.922 & $0 \%$ & 0.0004 & 0.0196 & 3314 \\
\hline & \multicolumn{4}{|c|}{ ANOVA $Q$ random effects test with separate estimates of $T^{2}$} & \multicolumn{2}{|r|}{$P=0.742$} & \multicolumn{2}{|c|}{ Total $N$} & 6462 \\
\hline \multirow[t]{4}{*}{ VAS-back } & Prospective study & 3 & 0.425 & 0.047 & 0.803 & $3 \%$ & 0.0371 & 0.1926 & 284 \\
\hline & Randomized prospective study & 11 & 0.806 & 0.653 & 0.959 & $0 \%$ & 0.0061 & 0.0780 & 1542 \\
\hline & Retrospective study & 15 & 0.715 & 0.587 & 0.843 & $0 \%$ & 0.0043 & 0.0653 & 2560 \\
\hline & \multicolumn{4}{|c|}{ ANOVA $Q$ random effects test with separate estimates of $T^{2}$} & \multicolumn{2}{|r|}{$P=0.112$} & \multicolumn{2}{|c|}{ Total $N$} & 4386 \\
\hline \multirow[t]{4}{*}{ VAS-leg } & Prospective study & 6 & 0.912 & 0.885 & 0.938 & $0 \%$ & 0.0002 & 0.0136 & 1632 \\
\hline & Randomized prospective study & 11 & 0.860 & 0.733 & 0.987 & $0 \%$ & 0.0042 & 0.0650 & 1542 \\
\hline & Retrospective study & 35 & 0.866 & 0.819 & 0.912 & $0 \%$ & 0.0006 & 0.0238 & 4716 \\
\hline & \multicolumn{4}{|c|}{ ANOVA $Q$ random effects test with separate estimates of $T^{2}$} & \multicolumn{2}{|r|}{$P=0.175$} & \multicolumn{2}{|c|}{ Total $N$} & 7890 \\
\hline
\end{tabular}

Abbreviations: ANOVA, analysis of variance; VAS, visual analog scale.

minimally invasive IPS placement combined with an endoscopic foraminal decompression reported similar findings. ${ }^{159}$ At a minimum, our meta-analysis substantiated the rationale for combining the IPS with endoscopy. However, it cannot replace a formal long-term study, which should be carried out as a prospective well-matched cohort study with a robust randomization protocol. Last but not least, implant-related problems may also need to be accounted for as their incidence is currently not known when combining these 2 minimally invasive surgeries both targeting spinal stenosis.

As discussed at the outset of this article, we were not interested in pushing endoscopic surgery in favor of IPS. We were only interested in reporting a reference data set of ODI, VAS-back, and VAS-leg ES in the form of reference tables (Tables 3-5) to aid in the ongoing discussion on how to improve the durability of MISST and how to most effectively transition modern spine care to more reliable and less costly procedures by replacing some of the traditional open with endoscopic spinal surgery whose reliability could be improved by performing it in conjunction with a stabilizing procedure, such as an IPS.

We expected to find significant heterogeneity in our meta-analysis. Heterogeneity may be unfavorable in meta-analyses of randomized trials of medical or pharmacotherapeutic interventions as it would suggest significant variability in the outcomes of highly protocolized interventions. In contrast, surgical procedures may follow protocols but its outcomes are also influenced significantly by many factors and class effects (see also below). In addition, disability and pain are subjective and patient outcomes that cannot be objectively scaled because of between-patient variability in appraisal, anchoring, and scaling. Furthermore, while previous meta-analyses were limited to prospective randomized trials, ${ }^{55,73-75,81,160-167}$ we included nonrandomized prospective studies as well as retrospective analyses. Despite the evidence that well-designed observational studies do not overestimate treatment effects as compared to those obtained in randomized trials, ${ }^{168,169}$ bias due to differences in the quality of studies and their designs cannot be negated. The use of random effects models in the analyses was intended to manage the observed heterogeneity.

The heterogeneity may also explain the publication bias found in our meta-analysis, a second limitation to be considered. Twenty-eight of the 48 studies included in this meta-analysis were retrospective. Many of these contributed to the spread of study-specific ES data in the 3 forest plots may have tended to cause the funnel plot to be asymmetric with many studies falling outside the funnel. Here too, the use of random effects models aimed to mitigate this bias. Heterogeneity and asymmetry may very well be inherent to surgical studies. Variation in patients' expectations; the subjectivity and relative lack of anchoring and scaling of disability ratings such as the ODI and the 2 VAS scales; differences in surgeons' skill level and preferences; variability in organizational process and procedural aspects of the surgery; surgery being carried out either in an outpatient ambulatory surgery center or in a hospital setting; and many other factors may be responsible for the heterogeneity observed in some of the subgroups as evidenced by some of the outliers. The differences found in the ODI, VAS-back, and VAS-leg ES are reflective of real-life clinical scenarios where spine care is delivered under a great variety of patient-related and system-related circumstances. The surgeon skill factor is likely the most relevant confounder in this whole analysis and may be responsible for the wide overlap in successful clinical outcomes regardless of 
the type of direct or indirect lumbar decompression surgery employed.

\section{CONCLUSIONS}

The classic indication for lumbar endoscopy has been lumbar herniation, but it has evolved to include stenosis as an indication. The indication for IPS is also lumbar spinal stenosis. Both spinal endoscopy and IPS address lumbar stenosis, albeit with different approach mechanisms, direct decompression vs indirect decompression. While the authors' hypothesis is supported by their statistical meta-analysis modeling and corroborated a limited clinical feasibility 2-year follow-up study on 33 patients, ${ }^{159}$ there is a need for a long-term follow-up comparison of endoscopy with and without IPS, where potential implant-related failures and complications also will have to be taken into account when analyzing the cost-benefit equation. In spite of these limitations and considering that we did not attempt a formal comparison of endoscopy to other MISSTs or traditional open surgical decompression, our metaanalysis supports a clinically important conclusion: the addition of IPS to transforaminal lumbar endoscopic foraminal decompression may improve outcomes by reducing the residual mechanical low back pain that is often observed with this attractive outpatient surgery. The ongoing debate on the merits of endoscopic spine surgery will likely continue; thus, the clinical merits of combining spinal endoscopy with IPS should be further studied. With this meta-analysis, we provided the statistical evidence required to have this debate in an objective manner where one wonders about the continued need for aggressive open surgeries for the indications investigated herein if the reported differences in ES gradients for clinical improvements are marginal.

\section{REFERENCES}

1. Lewandrowski KU, Ransom NA. Five-year clinical outcomes with endoscopic transforaminal outside-in foraminoplasty techniques for symptomatic degenerative conditions of the lumbar spine. J Spine Surg. 2020;6(Suppl 1):S54-S65. doi:10.21037/ jss.2019.07.03

2. Dowling Á, Lewandrowski K-U, da Silva FHP, Parra JAA, Portillo DM, Giménez YCP, et al. Patient selection protocols for endoscopic transforaminal, interlaminar, and translaminar decompression of lumbar spinal stenosis. J Spine Surg. 2020;6(Suppl 1):S120-S132. doi:10.21037/jss.2019.11.07

3. Katzell JL. Risk factors predicting less favorable outcomes in endoscopic lumbar discectomies. J Spine Surg. 2020;6(Suppl 1):S155-S164. doi:10.21037/jss.2019.11.04

4. Ahn J-S, Lee H-J, Choi D-J, Lee K-Y, Hwang S-J, et al. Extraforaminal approach of biportal endoscopic spinal surgery: a new endoscopic technique for transforaminal decompression and discectomy. J Neurosurg Spine. 2018;28(5):492-498. doi:10.3171/2017.8 .SPINE17771

5. Ahn Y, Keum HJ, Lee S-G, Lee S-W, et al. Transforaminal endoscopic decompression for lumbar lateral recess stenosis: an advanced surgical technique and clinical outcomes. World Neurosurg. 2019;125:e916-e924. doi:10.1016/j.wneu.2019.01.209

6. Choi DJ, Kim JE. Efficacy of biportal endoscopic spine surgery for lumbar spinal stenosis. Clin Orthop Surg. 2019;11(1):82-88. doi:10.4055/cios.2019.11.1.82

7. Chung J, Kong C, Sun W, Kim D, Kim H, Jeong H, et al. Percutaneous endoscopic lumbar foraminoplasty for lumbar foraminal stenosis of elderly patients with unilateral radiculopathy: radiographic changes in magnetic resonance images. J Neurol Surg A Cent Eur Neurosurg. 2019;80(4):302-311. doi:10.1055/s-0038-1677052

8. Eun SS, Eum JH, Lee SH, Sabal LA, et al. Biportal endoscopic lumbar decompression for lumbar disk herniation and spinal canal stenosis: a technical note. J Neurol Surg A Cent Eur Neurosurg. 2017;78(4):390-396. doi:10.1055/s-0036-1592157

9. Heo DH, Lee DC, Park CK. Comparative analysis of three types of minimally invasive decompressive surgery for lumbar central stenosis: biportal endoscopy, uniportal endoscopy, and microsurgery. Neurosurg Focus. 2019;46(5):2019.2.FOCUS197. doi:10.3171/2019.2.FOCUS197

10. Imajo $\mathrm{Y}$, Taguchi $\mathrm{T}$, Neo $\mathrm{M}$, et al. Complications of spinal surgery for elderly patients with lumbar spinal stenosis in a super-aging country: an analysis of 8033 patients. J Orthop Sci. 2017;22(1):10-15. doi:10.1016/j.jos.2016.08.014

11. An K-C, Kong G-M, Park D-H, Baik J-M, Youn J-H, Lee $\mathrm{W}-\mathrm{S}$, et al. Comparison of posterior lumbar interbody fusion and posterolateral lumbar fusion in monosegmental vacuum phenomenon within an intervertebral disc. Asian Spine J. 2016;10(1):93-98. doi:10.4184/asj.2016.10.1.93

12. Liao J-C, Lu M-L, Niu C-C, Chen W-J, Chen L-H, et al. Surgical outcomes of degenerative lumbar spondylolisthesis with anterior vacuum disc: can the intervertebral cage overcome intradiscal vacuum phenomenon and enhance posterolateral fusion? $J$ Orthop Sci. 2014;19(6):851-859. doi:10.1007/s00776-014-0618-z

13. Lin T-Y, Liao J-C, Tsai T-T, et al. The effects of anterior vacuum disc on surgical outcomes of degenerative versus spondylolytic spondylolisthesis: at a minimum two-year follow-up. BMC Musculoskelet Disord. 2014;15:329. doi:10.1186/1471-2474-15329

14. Murata K, Akeda K, Takegami N, Cheng K, Masuda K, Sudo A, et al. Morphology of intervertebral disc ruptures evaluated by vacuum phenomenon using multi-detector computed tomography: association with lumbar disc degeneration and canal stenosis. BMC Musculoskelet Disord. 2018;19(1):164. doi:10.1186/s12891018-2086-7

15. Söffler C, Karpenstein H, Kramer M. The intervertebral vacuum phenomenon as a computed-tomographic finding in the dog and its significance as an indicator for surgical treatment of vertebral disc herniations. Tierarztl Prax Ausg K Kleintiere Heimtiere. 2014;42(2):88-93. doi:10.1055/s-0038-1623746

16. Schweitzer ME, el-Noueam KI. Vacuum disc: frequency of high signal intensity on T2-weighted MR images. Skeletal Radiol. 1998;27(2):83-86. doi:10.1007/s002560050342

17. Lewandrowski K-U, León JFR, Yeung A. Use of "insideout" technique for direct visualization of a vacuum vertically unstable intervertebral disc during routine lumbar endoscopic transforaminal decompression-a correlative study of clinical outcomes 
and the prognostic value of lumbar radiographs. Int J Spine Surg. 2019;13(5):399-414. doi:10.14444/6055

18. Sebro R, O'Brien L, Torriani M, Bredella MA, et al. Assessment of trunk muscle density using CT and its association with degenerative disc and facet joint disease of the lumbar spine. Skeletal Radiol. 2016;45(9):1221-1226. doi:10.1007/s00256-0162405-8

19. Sun D, Liu P, Cheng J, Ma Z, Liu J, Qin T, et al. Correlation between intervertebral disc degeneration, paraspinal muscle atrophy, and lumbar facet joints degeneration in patients with lumbar disc herniation. BMC Musculoskelet Disord. 2017;18(1):167. doi:10.1186/s12891-017-1522-4

20. Yoshiiwa T, Miyazaki M, Notani N, Ishihara T, Kawano M, Tsumura H, et al. Analysis of the relationship between ligamentum flavum thickening and lumbar segmental instability, disc degeneration, and facet joint osteoarthritis in lumbar spinal stenosis. Asian Spine J. 2016;10(6):1132-1140. doi:10.4184/asj.2016.10.6.1132

21. Yeung A, Lewandrowski KU. Five-year clinical outcomes with endoscopic transforaminal foraminoplasty for symptomatic degenerative conditions of the lumbar spine: a comparative study of inside-out versus outside-in techniques. J Spine Surg. 2020;6(Suppl 1):S66-S83. doi:10.21037/jss.2019.06.08

22. Lewandrowski KU. Incidence, management, and cost of complications after transforaminal endoscopic decompression surgery for lumbar foraminal and lateral recess stenosis: a value proposition for outpatient ambulatory surgery. Int J Spine Surg. 2019;13(1):53-67. doi:10.14444/6008

23. Lewandrowski KU. Readmissions after outpatient transforaminal decompression for lumbar foraminal and lateral recess stenosis. Int J Spine Surg. 2018;12(3):342-351. doi:10.14444/5040

24. Yeung A, Roberts A, Zhu L, Qi L, Zhang J, Lewandrowski $\mathrm{K}-\mathrm{U}$, et al. Treatment of soft tissue and bony spinal stenosis by a visualized endoscopic transforaminal technique under local anesthesia. Neurospine. 2019;16(1):52-62. doi:10.14245/ns.1938038.019

25. Ahn Y, Lee U, Kim W-K, Keum HJ, et al. Five-year outcomes and predictive factors of transforaminal full-endoscopic lumbar discectomy. Medicine (Baltimore). 2018;97(48):e13454. doi:10.1097/MD.0000000000013454

26. Fischgrund JS, Rhyne A, Franke J, et al. Intraosseous basivertebral nerve ablation for the treatment of chronic low back pain: 2-year results from a prospective randomized double-blind sham-controlled multicenter study. Int J Spine Surg. 2019;13(2):110-119. doi:10.14444/6015

27. Katzell JL. Risk factors predicting less favorable outcomes in endoscopic lumbar discectomies. J Spine Surg. 2020;6(Suppl 1):S155-S164. doi:10.21037/jss.2019.11.04

28. Knight M, Goswami A. Lumbar percutaneous KTP532 wavelength laser disc decompression and disc ablation in the management of discogenic pain. J Clin Laser Med Surg. 2002;20(1):9-13. doi:10.1089/104454702753474940

29. Knight MT, Ellison DR, Goswami A, Hillier VF, et al. Review of safety in endoscopic laser foraminoplasty for the management of back pain. J Clin Laser Med Surg. 2001;19(3):147-157. doi:10.1089/10445470152927982

30. Lee SH, Kang HS. Percutaneous endoscopic laser annuloplasty for discogenic low back pain. World Neurosurg. 2010;73(3):198-206. doi:10.1016/j.surneu.2009.01.023

31. Lewandrowski K-U, Ransom NA, Ramírez León JF, Yeung A, et al. The concept for a standalone lordotic endoscopic wedge lumbar interbody fusion: the LEW-LIF. Neurospine. 2019;16(1):82-95. doi:10.14245/ns.1938046.023
32. Ramírez León JF, Ardila ÁS, Rugeles Ortíz JG, et al. Standalone lordotic endoscopic wedge lumbar interbody fusion (LEW-LIF) with a threaded cylindrical peek cage: report of two cases. J Spine Surg. 2020;6(Suppl 1):S275-S284. doi:10.21037/ jss.2019.06.09

33. Liu G, Zhao JN, Dezawa A. Endoscopic decompression combined with interspinous process implant fusion for lumbar spinal stenosis. Chin J Traumatol. 2008;11(6):364-367. doi:10.1016/ s1008-1275(08)60073-5

34. Bini W, Miller LE, Block JE. Minimally invasive treatment of moderate lumbar spinal stenosis with the superion interspinous spacer. Open Orthop J. 2011;5:361-367. doi: 10.2174/1874325001105010361

35. Loguidice V, Bini W, Shabat S, Miller LE, Block JE, et al. Rationale, design and clinical performance of the superion ${ }^{\circledR}$ interspinous spacer: a minimally invasive implant for treatment of lumbar spinal stenosis. Expert Rev Med Devices. 2011;8(4):419-426. doi:10.1586/erd.11.24

36. Merkow J, Varhabhatla N, Manchikanti L, Kaye AD, Urman RD, Yong RJ, et al. Minimally invasive lumbar decompression and interspinous process device for the management of symptomatic lumbar spinal stenosis: a literature review. Curr Pain Headache Rep. 2020;24(4):13. doi:10.1007/s11916-020-0845-2

37. Shabat S, Miller LE, Block JE, Gepstein R, et al. Minimally invasive treatment of lumbar spinal stenosis with a novel interspinous spacer. Clin Interv Aging. 2011;6:227-233. doi:10.2147/ CIA.S23656

38. Arrotegui I. Coflex interspinous spacer. Use in degenerative lumbar disc herniation. Acta Ortop Mex. 2010;24(3):187-190.

39. Chen Y-H, Xu D, Xu H-Z, Chi Y-L, Wang X-Y, Huang Q$\mathrm{S}$, et al. Coflex interspinous dynamic internal fixation for the treatment of degenerative lumbar spinal stenosis. Zhongguo Gu Shang. 2009;22(12):902-905.

40. Chiu JC. Interspinous process decompression (IPD) system (X-STOP) for the treatment of lumbar spinal stenosis. Surg Technol Int. 2006;15:265-275.

41. Hartjen CA, Resnick DK, Hsu KY, Zucherman JF, Hsu EH, Skidmore GA, et al. Two-year evaluation of the X-STOP interspinous spacer in different primary patient populations with neurogenic intermittent claudication because of lumbar spinal stenosis. Clin Spine Surg. 2016;29(7):305-311. doi:10.1097/ BSD.0b013e31827b671f

42. Masala S, Marcia S, Taglieri A, et al. Degenerative lumbar spinal stenosis treatment with Aperius PerCLID system and Falena(R) interspinous spacers: 1-year follow-up of clinical outcome and quality of life. Interv Neuroradiol. 2016;22(2):217-226. doi: $10.1177 / 1591019915622163$

43. Menchetti PPM, Postacchini F, Bini W, Canero G, et al. Percutaneous surgical treatment in lumbar spinal stenosis with AperiusPercLID: indications, surgical technique and results. Acta Neurochir Suppl. 2011;108:183-186. doi:10.1007/978-3-211-99370-5_27

44. Nicholson JA, Scott CEH, Duckworth AD, Burke JG, Gibson JNA, et al. Survival analysis of the wallis interspinous spacer used as an augment to lumbar decompression. Br J Neurosurg. 2017;31(6):688-694. doi:10.1080/02688697.2017.1351522

45. Lauryssen C, Jackson RJ, Baron JM, et al. Stand-alone interspinous spacer versus decompressive laminectomy for treatment of lumbar spinal stenosis. Expert Rev Med Devices. 2015;12(6):763-769. doi:10.1586/17434440.2015.1100071

46. Miller LE, Block JE. Interspinous spacer implant in patients with lumbar spinal stenosis: preliminary results of a multicenter, 
randomized, controlled trial. Pain Res Treat. 2012;2012:823509. doi:10.1155/2012/823509

47. Nunley PD, Patel VV, Orndorff DG, Block J, Lavelle WF, Geisler F. Four-year results of a randomized controlled trial for treatment of moderate lumbar spinal stenosis with InterSpinous spacer. The Spine Journal. 2017;17(10):S265. doi:10.1016/j. spinee.2017.08.201

48. Nunley PD, Patel VV, Orndorff DG, Lavelle WF, Block JE, Geisler FH. Five-year durability of stand-alone interspinous process decompression for lumbar spinal stenosis. Clin Interv Aging. 2017;12:1409-1417. doi:10.2147/CIA.S143503

49. Nunley PD, Patel VV, Orndorff DG, Lavelle WF, Block JE, Geisler FH. Interspinous process decompression improves quality of life in patients with lumbar spinal stenosis. Minim Invasive Surg. 2018;2018:1035954. doi:10.1155/2018/1035954

50. Nunley PD, Shamie AN, Blumenthal SL, Orndorff D, Block JE, Geisler FH, et al. Interspinous process decompression: expanding treatment options for lumbar spinal stenosis. Biomed Res Int. 2016;2016:3267307. doi:10.1155/2016/3267307

51. Parker SL, Anderson LH, Nelson T, Patel VV, et al. Costeffectiveness of three treatment strategies for lumbar spinal stenosis: conservative care, laminectomy, and the superion interspinous spacer. Int J Spine Surg. 2015;9:28. doi:10.14444/2028

52. Patel VV, Whang PG, Haley TR, et al. Superion interspinous process spacer for intermittent neurogenic claudication secondary to moderate lumbar spinal stenosis: two-year results from a randomized controlled FDA-IDE pivotal trial. Spine (Phila Pa 1976). 2015;40(5):275-282. doi:10.1097/ BRS.0000000000000735

53. Patel VV, Whang PG, Haley TR, et al. Two-year clinical outcomes of a multicenter randomized controlled trial comparing two interspinous spacers for treatment of moderate lumbar spinal stenosis. BMC Musculoskelet Disord. 2014;15:221. doi:10.1186/14712474-15-221

54. Whang PG, Patel VV, Bradley WD, Block JE, et al. Midterm outcomes of a prospective multicenter randomized controlled trial comparing the clinical efficacy of interspinous spacers as a treatment for moderate lumbar spinal stenosis. The Spine Journal. 2013;13(9):S136-S137. doi:10.1016/j.spinee.2013.07.352

55. Zhao H, Duan L-J, Gao Y-S, et al. Comparison of two FDA-approved interspinous spacers for treatment of lumbar spinal stenosis: superion versus X-STOP-a meta-analysis from five randomized controlled trial studies. J Orthop Surg Res. 2018;13(1):42. doi:10.1186/s13018-018-0742-0

56. Cairns K, Deer T, Sayed D, van Noort K, Liang K, et al. Cost-effectiveness and safety of interspinous process decompression (superion). Pain Med. 2019;20(Suppl 2):S2-S8. doi:10.1093/ $\mathrm{pm} / \mathrm{pnz} 245$

57. Yaghoubi M, Moradi-Lakeh M, Moradi-Joo M, RahimiMovaghar V, Zamani N, Naghibzadeh-Tahami A, et al. The cost effectiveness of dynamic and static interspinous spacer for lumbar spinal stenosis compared with laminectomy. Med J Islam Repub Iran. 2016;30:339.

58. Neely WF, Fichtel F, Del Monaco DC, Block JE, et al. Treatment of symptomatic lumbar disc degeneration with the VariLift-L interbody fusion system: retrospective review of 470 cases. Int J Spine Surg. 2016;10:15. doi:10.14444/3015

59. Kepler CK, Rihn JA, Radcliff KE, et al. Restoration of lordosis and disk height after single-level transforaminal lumbar interbody fusion. Orthop Surg. 2012;4(1):15-20. doi:10.1111/ j.1757-7861.2011.00165.x
60. Liu E, Yin Q, Guo D. Long-term follow-up study on expandable Cage in treatment of degenerative lumbar disease. Zhongguo Xiu Fu Chong Jian Wai Ke Za Zhi. 2014;28(5):540-543.

61. Ahn Y, Kim W-K, Son S, Lee S-G, Jeong YM, Im T, et al. Radiographic assessment on magnetic resonance imaging after percutaneous endoscopic lumbar foraminotomy. Neurol Med Chir (Tokyo). 2017;57(12):649-657. doi:10.2176/nmc.oa.2016-0249

62. Kim CW, Doerr TM, Luna IY, et al. Minimally invasive transforaminal lumbar interbody fusion using expandable technology: a clinical and radiographic analysis of 50 patients. World Neurosurg. 2016;90:228-235. doi:10.1016/j.wneu.2016.02.075

63. Hawasli AH, Khalifeh JM, Chatrath A, Yarbrough CK, Ray WZ, et al. Minimally invasive transforaminal lumbar interbody fusion with expandable versus static interbody devices: radiographic assessment of sagittal segmental and pelvic parameters. Neurosurg Focus. 2017;43(2):E10. doi:10.3171/2017.5.FOCUS17197

64. Kale A, Oz II, Onk A, Kalaycı M, Büyükuysal Ç. Unilaterally posterior lumbar interbody fusion with double expandable peek cages without pedicle screw support for lumbar disc herniation. Neurol Neurochir Pol. 2017;51(1):53-59. doi:10.1016/j. pjnns.2016.11.001

65. Yee TJ, Joseph JR, Terman SW, Park P. Expandable vs static cages in transforaminal lumbar interbody fusion: radiographic comparison of segmental and lumbar sagittal angles. Neurosurgery. 2017;81(1):69-74. doi:10.1093/neuros/nyw177

66. Parker SL, Mendenhall SK, Godil SS, et al. Incidence of low back pain after lumbar discectomy for herniated disc and its effect on patient-reported outcomes. Clin Orthop Relat Res. 2015;473(6):1988-1999. doi:10.1007/s11999-015-4193-1

67. Wang H, Zhou Y, Li C, Liu J, Xiang L, et al. Risk factors for failure of single-level percutaneous endoscopic lumbar discectomy. J Neurosurg Spine. 2015;23(3):320-325. doi:10.3171/2014.10. SPINE1442

68. Kong DS, Kim ES, Eoh W. One-year outcome evaluation after interspinous implantation for degenerative spinal stenosis with segmental instability. J Korean Med Sci. 2007;22(2):330-335. doi:10.3346/jkms.2007.22.2.330

69. Cabraja M, Abbushi A, Woiciechowsky C, Kroppenstedt S, et al. The short- and mid-term effect of dynamic interspinous distraction in the treatment of recurrent lumbar facet joint pain. Eur Spine J. 2009;18(11):1686-1694. doi:10.1007/s00586-009-1149-8

70. Errico TJ, Kamerlink JR, Quirno M, Samani J, Chomiak RJ. Survivorship of coflex interlaminar-interspinous implant. SAS J. 2009;3(2):59-67. doi:10.1016/SASJ-2008-0027-RR

71. Buric J, Pulidori M. Long-term reduction in pain and disability after surgery with the interspinous device for intervertebral assisted motion (DIAM) spinal stabilization system in patients with low back pain: 4-year follow-up from a longitudinal prospective case series. Eur Spine J. 2011;20(8):1304-1311. doi:10.1007/ s00586-011-1697-6

72. Rouben D, Casnellie M, Ferguson M. Long-term durability of minimal invasive posterior transforaminal lumbar interbody fusion. J Spinal Disord Tech. 2011;24(5):288-296. doi:10.1097/ BSD.0b013e3181f9a60a

73. Moojen WA, Arts MP, Bartels RHMA, Jacobs WCH, Peul WC, et al. Effectiveness of interspinous implant surgery in patients with intermittent neurogenic claudication: a systematic review and meta-analysis. Eur Spine J. 2011;20(10):1596-1606. doi:10.1007/ s00586-011-1873-8

74. Machado GC, Ferreira PH, Harris IA, et al. Effectiveness of surgery for lumbar spinal stenosis: a systematic review and 
meta-analysis. PLoS ONE. 2015;10(3):e0122800. doi:10.1371/ journal.pone. 0122800

75. Phan K, Rao PJ, Ball JR, Mobbs RJ. Interspinous process spacers versus traditional decompression for lumbar spinal stenosis: systematic review and meta-analysis. J Spine Surg. 2016;2(1):31-40. doi:10.21037/jss.2016.01.07

76. Ravindra VM, Ghogawala Z. Is there still a role for interspinous spacers in the management of neurogenic claudication? Neurosurgery Clinics of North America. 2017;28(3):321-330. doi:10.1016/j.nec.2017.02.002

77. Fairbank J. Use of oswestry disability index (ODI). Spine (Phila Pa 1976). 1995;20(13):1535-1537. doi:10.1097/00007632199507000-00020

78. Fairbank JCT, Pynsent PB. The oswestry disability index. Spine (Phila Pa 1976). 2000;25(22):2940-2952. doi:10.1097/00007632-200011150-00017

79. van Hooff ML, Spruit M, Fairbank JCT, van Limbeek J, Jacobs WCH, et al. The oswestry disability index (version 2.1a): validation of a Dutch language version. Spine (Phila Pa 1976). 2015;40(2):E83-90. doi:10.1097/BRS.0000000000000683

80. Reed CC, Wolf WA, Cotton CC, Dellon ES, et al. A visual analogue scale and a Likert scale are simple and responsive tools for assessing dysphagia in eosinophilic oesophagitis. Aliment Pharmacol Ther. 2017;45(11):1443-1448. doi:10.1111/apt.14061

81. Zhang B, Liu S, Liu J, et al. Transforaminal endoscopic discectomy versus conventional microdiscectomy for lumbar discherniation: a systematic review and meta-analysis. J Orthop Surg Res. 2018;13(1):169. doi:10.1186/s13018-018-0868-0

82. Hutton B, Salanti G, Caldwell DM, et al. The PRISMA extension statement for reporting of systematic reviews incorporating network meta-analyses of health care interventions: checklist and explanations. Ann Intern Med. 2015;162(11):777-784. doi:10.7326/M14-2385

83. Liberati A, Altman DG, Tetzlaff J, et al. The PRISMA statement for reporting systematic reviews and meta-analyses of studies that evaluate healthcare interventions: explanation and elaboration. BMJ. 2009;339:bmj.b2700. doi:10.1136/bmj.b2700

84. Liu H, Zhou X, Yu G, Sun X, et al. The effects of the PRISMA statement to improve the conduct and reporting of systematic reviews and meta-analyses of nursing interventions for patients with heart failure. Int J Nurs Pract. 2019;25(3):e12729. doi:10.1111/ijn.12729

85. McGrath LB, White-Dzuro GA, Hofstetter CP. Comparison of clinical outcomes following minimally invasive or lumbar endoscopic unilateral laminotomy for bilateral decompression. J Neurosurg Spine. 2019;30(4):491-499. doi:10.3171/2018.9.SPINE18689

86. McInnes MDF, Moher D, Thombs BD, et al. Preferred reporting items for a systematic review and meta-analysis of diagnostic test accuracy studies: the PRISMA-DTA statement. JAMA. 2018;319(4):388-396. doi:10.1001/jama.2017.19163

87. Page MJ, Moher D. Evaluations of the uptake and impact of the preferred reporting items for systematic reviews and metaanalyses (PRISMA) statement and extensions: a scoping review. Syst Rev. 2017;6(1):263. doi:10.1186/s13643-017-0663-8

88. Poveda-Montoyo I, Belinchón-Romero I, Romero-Pérez D, Ramos-Rincón JM, et al. Topics and PRISMA checklist compliance for meta-analyses in dermatology: journal case study. Acta Dermatovenerol Croat. 2019;27(4):275-277.

89. Moher D, Shamseer L, Clarke M, et al. Preferred reporting items for systematic review and meta-analysis protocols (PRISMA-P) 2015 statement. Syst Rev. 2015;4:1. doi:10.1186/2046-4053-4-1
90. Hara N, Matsudaira K, Masuda K, et al. Psychometric assessment of the Japanese version of the Zurich claudication questionnaire (ZCQ): reliability and validity. PLoS One. 2016;11(7):e0160183. doi:10.1371/journal.pone.0160183

91. Hidalgo Ovejero AM, Menéndez García M, Bermejo Fraile B, García Mata S, Forcén Alonso T, Mateo Sebastián P, et al. Cross-cultural adaptation of the Zurich claudication questionnaire. Validation study of the Spanish version. An Sist Sanit Navar. 2015;38(1):41-52. doi:10.23938/ASSN.0052

92. Kim H-J, Lee Y-K, Kim DO, Chang B-S, Lee C-K, Yeom JS, et al. Validation and cross-cultural adaptation of the Korean version of the Zurich claudication questionnaire in patients with lumbar spinal stenosis. Spine. 2018;43(2):E105-E110. doi:10.1097/ BRS.0000000000002241

93. Saltychev M, Virolainen P. Validation and cross-cultural adaptation of the Korean version of the Zurich claudication questionnaire in patients with lumbar spinal stenosis. Spine (Phila Pa 1976). 2018.

94. Cohen J. Statistical Power Analysis for the Behavioral Sciences. Hillsdale, NJ: Publisher unknown; 1988.

95. COHEN J. The statistical power of abnormal-social psychological research: a review. J Abnorm Soc Psychol. 1962;65:145-153. doi:10.1037/h0045186

96. Azimi P, Yazdanian T, Benzel EC. Determination of minimally clinically important differences for JOABPEQ measure after discectomy in patients with lumbar disc herniation. J Spine Surg. 2018;4(1):102-108. doi:10.21037/jss.2018.03.11

97. Cook CE. Clinimetrics corner: the minimal clinically important change score (MCID): a necessary pretense. J Man Manip Ther. 2008;16(4):E82-3. doi:10.1179/jmt.2008.16.4.82E

98. Copay AG, Eyberg B, Chung AS, Zurcher KS, Chutkan N, Spangehl MJ, et al. Minimum clinically important difference: current trends in the orthopaedic literature, part ii: lower extremity: a systematic review. JBJS Rev. 2018;6(9):e2. doi:10.2106/JBJS. RVW.17.00160

99. Held U, Burgstaller JM, Wertli MM, et al. Prognostic function to estimate the probability of meaningful clinical improvement after surgery - Results of a prospective multicenter observational cohort study on patients with lumbar spinal stenosis. PLoS One. 2018;13(11):e0207126. doi:10.1371/journal.pone. 0207126

100. Jaeschke R, Singer J, Guyatt GH. Measurement of health status. Ascertaining the minimal clinically important difference. Control Clin Trials. 1989;10(4):407-415. doi:10.1016/01972456(89)90005-6

101. Lauridsen HH, Hartvigsen J, Manniche C, Korsholm L, Grunnet-Nilsson N, et al. Responsiveness and minimal clinically important difference for pain and disability instruments in low back pain patients. BMC Musculoskelet Disord. 2006;7:82. doi:10.1186/1471-2474-7-82

102. Ahn Y, Lee SG, Son S, Keum HJ, et al. Transforaminal endoscopic lumbar discectomy versus open lumbar microdiscectomy: a comparative cohort study with a 5-year follow-up. Pain Physician. 2019;22(3):295-304.

103. Bai Y, Xu L, Xi J, Mu X, et al. Diagnosis and treatment of lumbar disc herniation by discography and percutaneous transforaminal endoscopic surgery. Zhonghua Yi Xue Za Zhi. 2012;92(47):3350-3353.

104. Choi G, Lee S-H, Bhanot A, Raiturker PP, Chae YS, et al. Percutaneous endoscopic discectomy for extraforaminal lumbar disc herniations: extraforaminal targeted fragmentectomy 
technique using working channel endoscope. Spine (Phila Pa 1976). 2007;32(2):E93-9. doi:10.1097/01.brs.0000252093.31632.54

105. Choi G, Modi HN, Prada N, et al. Clinical results of XMRassisted percutaneous transforaminal endoscopic lumbar discectomy. J Orthop Surg Res. 2013;8:14. doi:10.1186/1749-799X-8-14

106. Choi KC, Kim JS, Park CK. Percutaneous endoscopic lumbar discectomy as an alternative to open lumbar microdiscectomy for large lumbar disc herniation. Pain Physician. 2016;19(2):E291-300. doi:10.36076/ppj/2016.19.E291

107. Choi KC, Park CK. Percutaneous endoscopic lumbar discectomy for L5-S1 disc herniation: consideration of the relation between the iliac crest and L5-S1 disc. Pain Physician. 2016;19(2):E301-8.

108. Dey PC, Nanda SN. Functional outcome after endoscopic lumbar discectomy by destandau's technique: a prospective study of 614 patients. Asian Spine J. 2019;13(5):786-792. doi:10.31616/ asj.2018.0320

109. Eun SS, Lee SH, Erken HY. Transforaminal percutaneous endoscopic lumbar diskectomy for downmigrated disk herniations: lever-up, rotate, and tilt technique. J Neurol Surg A Cent Eur Neurosurg. 2018;79(2):163-168. doi:10.1055/s-0037-1608837

110. Gibson JNA, Subramanian AS, Scott CEH. A randomised controlled trial of transforaminal endoscopic discectomy vs microdiscectomy. Eur Spine J. 2017;26(3):847-856. doi:10.1007/s00586016-4885-6

111. Kim HS, Adsul N, Kapoor A, et al. A mobile outside-in technique of transforaminal lumbar endoscopy for lumbar disc herniations. J Vis Exp. 2018;(138). doi:10.3791/57999

112. Kim JE, Choi DJ. Bi-portal arthroscopic spinal surgery (BASS) with $30^{\circ}$ arthroscopy for far lateral approach of L5-S1 Technical note. J Orthop. 2018;15(2):354-358. doi:10.1016/j. jor.2018.01.034

113. Komp M, Hahn P, Ozdemir S, et al. Operation of lumbar zygoapophyseal joint cysts using a full-endoscopic interlaminar and transforaminal approach: prospective 2-year results of 74 patients. Surg Innov. 2014;21(6):605-614. doi:10.1177/1553350614525668

114. Li H, Jiang C, Mu X, Lan W, Zhou Y, Li C, et al. Comparison of MED and PELD in the treatment of adolescent lumbar disc herniation: a 5-year retrospective follow-up. World Neurosurg. 2018;112:e255-e260. doi:10.1016/j.wneu.2018.01.030

115. Liu C, Chu L, Yong H-C, Chen L, Deng Z-L, et al. Percutaneous endoscopic lumbar discectomy for highly migrated lumbar disc herniation. Pain Physician. 2017;20(1):E75-E84. doi:10.36076/ppj.2017.1.E75

116. Pan F, Shen B, Chy SK, et al. Transforaminal endoscopic system technique for discogenic low back pain: a prospective cohort study. Int J Surg. 2016;35:134-138. doi:10.1016/j.ijsu.2016.09.091

117. Soliman HM. Irrigation endoscopic discectomy: a novel percutaneous approach for lumbar disc prolapse. Eur Spine J. 2013;22(5):1037-1044. doi:10.1007/s00586-013-2701-0

118. Song $\mathrm{H}, \mathrm{Hu} \mathrm{W}$, Liu Z, Hao Y, Zhang X, et al. Percutaneous endoscopic interlaminar discectomy of L5-S1 disc herniation: a comparison between intermittent endoscopy technique and full endoscopy technique. J Orthop Surg Res. 2017;12(1):162. doi:10.1186/s13018-017-0662-4

119. Teli M, Lovi A, Brayda-Bruno M, et al. Higher risk of dural tears and recurrent herniation with lumbar micro-endoscopic discectomy. Eur Spine J. 2010;19(3):443-450. doi:10.1007/s00586010-1290-4

120. Tu Z, Li YW, Wang B, et al. Clinical outcome of fullendoscopic interlaminar discectomy for single-level lumbar disc herniation: a minimum of 5-year follow-up. Pain Physician. 2017;20(3):E425-E430. doi:10.36076/ppj.2017.E430

121. Tu Z, Wang B, Li L, et al. Early experience of fullendoscopic interlaminar discectomy for adolescent lumbar disc herniation with sciatic scoliosis. Pain Physician. 2018;21(1):E63-E70. doi:10.36076/ppj.2018.1.E63

122. Zhang WMet al. Transforaminal endoscopic discectomy for treatment of central disc herniation: surgical techniques and clinical outcome. Pain Phys. 2018;1(21;1):E113-E123. doi:10.36076/ ppj.2018.2.E113. https://www.painphysicianjournal.com/current/ past?journal $=109$

123. Wang Y-P, Zhang W, An J-L, Zhang J, Bai J-Y, Sun Y-P, et al. Evaluation of transforaminal endoscopic discectomy in treatment of obese patients with lumbar disc herniation. Med Sci Monit. 2016;22:2513-2519. doi:10.12659/msm.899510

124. Xu B, Xu H, Ma X, et al. Bilateral decompression and intervertebral fusion via unilateral fenestration for complex lumbar spinal stenosis with a mobile microendoscopic technique. Medicine. 2018;97(4):e9715. doi:10.1097/MD.0000000000009715

125. Youn MS, Shin JK, Goh TS, Son SM, Lee JS, et al. Endoscopic posterior decompression under local anesthesia for degenerative lumbar spinal stenosis. J Neurosurg Spine. 2018;29(6):661-666. doi:10.3171/2018.5.SPINE171337

126. Zhang B, Kong Q, Yang J, Feng P, Ma J, Liu J, et al. Short-term effectiveness of percutaneous endoscopic transforaminal bilateral decompression for severe central lumbar spinal stenosis. Zhongguo Xiu Fu Chong Jian Wai Ke Za Zhi. 2019;33(11):1399-1405. doi:10.7507/1002-1892.201904131

127. Lewandrowski K-U, de Carvalho PST, Calderaro AL, et al. Outcomes with transforaminal endoscopic versus percutaneous laser decompression for contained lumbar herniated disc: a survival analysis of treatment benefit. J Spine Surg. 2020;6(Suppl 1):S84-S99. doi:10.21037/jss.2019.09.13

128. Abdel Ghany W, Amer A, Saeed K, et al. Evaluation of interspinous spacer outcomes in degenerative lumbar canal stenosis: clinical study. World Neurosurg. 2016;95(556-64):556-564. doi:10.1016/j.wneu.2016.07.095

129. Haley TR, Miller LE, Block JE. Mid-term outcomes of a prospective randomized controlled trial of interspinous spacer treatment for moderate lumbar spinal stenosis. $P M \& R$. 2013;5:S287-S287. doi:10.1016/j.pmrj.2013.08.510

130. Korovessis P, Syrimpeis V, Tsekouras V, Vardakastanis $\mathrm{K}$, Fennema $\mathrm{P}$, et al. PEEK versus silicon interspinous spacer for reduction of supradjacent segment degeneration following decompression and short-segment instrumentation for degenerative lumbar spinal stenosis. Adv Orthop. 2018;2018:1623647. doi:10.1155/2018/1623647

131. Gu H, Chang Y, Zeng S, et al. Wallis interspinous spacer for treatment of primary lumbar disc herniation: threeyear results of a randomized controlled trial. World Neurosurg. 2018;120:e1331-e1336. doi:10.1016/j.wneu.2018.09.086

132. Lønne G, Johnsen LG, Aas E, et al. Comparing costeffectiveness of X-stop with minimally invasive decompression in lumbar spinal stenosis. Spine (Phila Pa 1976). 2015;40(8):514-520. doi:10.1097/BRS.0000000000000798

133. Masala S, Fiori R, Bartolucci DA, et al. Percutaneous decompression of lumbar spinal stenosis with a new interspinous device. Cardiovasc Intervent Radiol. 2012;35(2):368-374. doi:10.1007/s00270-011-0167-1

134. Nunley PD, Patel VV, Orndorff DG, Lavelle WF, Block JE, Geisler FH. Superion interspinous spacer treatment of moderate 
spinal stenosis: 4-year results. World Neurosurg. 2017;104:279-283. doi:10.1016/j.wneu.2017.04.163

135. Postacchini R, Ferrari E, Cinotti G, Menchetti PPM, Postacchini F, et al. Aperius interspinous implant versus open surgical decompression in lumbar spinal stenosis. Spine $J$. 2011;11(10):933-939. doi:10.1016/j.spinee.2011.08.419

136. Richter A, Schütz C, Hauck M, Halm H, et al. Does an interspinous device (Coflex) improve the outcome of decompressive surgery in lumbar spinal stenosis? One-year follow up of a prospective case control study of 60 patients. Eur Spine J. 2010;19(2):283-289. doi:10.1007/s00586-009-1229-9

137. Sénégas J. Mechanical supplementation by non-rigid fixation in degenerative intervertebral lumbar segments: the wallis system. Eur Spine J. 2002;11 Suppl 2:S164-9. doi:10.1007/s00586002-0423-9

138. Surace MF, Fagetti A, Fozzato S, Cherubino P, et al. Lumbar spinal stenosis treatment with aperius perclid interspinous system. Eur Spine J. 2012;21 Suppl 1:S69-74. doi:10.1007/s00586012-2222-2

139. Strömqvist BH, Berg S, Gerdhem P, et al. X-stop versus decompressive surgery for lumbar neurogenic intermittent claudication: randomized controlled trial with 2-year follow-up. Spine (Phila Pa 1976). 2013;38(17):1436-1442. doi:10.1097/ BRS.0b013e31828ba413

140. Tekmyster G, Sayed D, Cairns KD, Raso LJ, Kim C, Block JE, et al. Interspinous process decompression with the superion ${ }^{\circledR}$ spacer for lumbar spinal stenosis: real-world experience from a device registry. Med Devices (Auckl). 2019;12:423-427. doi:10.2147/MDER.S220431

141. Puzzilli F, Gazzeri R, Galarza M, et al. Interspinous spacer decompression (X-STOP) for lumbar spinal stenosis and degenerative disk disease: a multicenter study with a minimum 3-year follow-up. Clin Neurol Neurosurg. 2014;124:166-174. doi:10.1016/j. clineuro.2014.07.004

142. Sobottke R, Schlüter-Brust K, Kaulhausen T, et al. Interspinous implants (X Stop, Wallis, Diam) for the treatment of LSS: is there a correlation between radiological parameters and clinical outcome? Eur Spine J. 2009;18(10):1494-1503. doi:10.1007/ s00586-009-1081-y

143. Yeung A, Lewandrowski KU. Early and staged endoscopic management of common pain generators in the spine. J Spine Surg. 2020;6(Suppl 1):S1-S5. doi:10.21037/jss.2019.09.03

144. Kantelhardt SR, Török E, Gempt J, et al. Safety and efficacy of a new percutaneously implantable interspinous process device. Acta Neurochir (Wien). 2010;152(11):1961-1967. doi:10.1007/s00701-010-0740-4

145. Park S-C, Yoon SH, Hong Y-P, Kim K-J, Chung S-K, Kim $\mathrm{H}-\mathrm{J}$, et al. Minimum 2-year follow-up result of degenerative spinal stenosis treated with interspinous u (coflex). J Korean Neurosurg Soc. 2009;46(4):292-299. doi:10.3340/jkns.2009.46.4.292

146. Patel VV, Nunley PD, Whang PG, et al. Superion ${ }^{\circledR}$ interSpinous spacer for treatment of moderate degenerative lumbar spinal stenosis: durable three-year results of a randomized controlled trial. J Pain Res. 2015;8:657-662. doi:10.2147/JPR.S92633

147. Richter A, Halm HFH, Hauck M, Quante M, et al. Twoyear follow-up after decompressive surgery with and without implantation of an interspinous device for lumbar spinal stenosis. J Spinal Disord Tech. 2014;27(6):336-341. doi:10.1097/ BSD.0b013e31825f7203

148. Sobottke R, Röllinghoff M, Siewe J, et al. Clinical outcomes and quality of life 1 year after open microsurgical decompression or implantation of an interspinous stand-alone spacer. Minim Invasive Neurosurg. 2010;53(04):179-183. doi:10.1055/s-0030-1263108

149. Block JE, Lavelle WF, Nunley PD. Toward a cure for lumbar spinal stenosis: the potential of interspinous process decompression. Medical Hypotheses. 2019;132:109357. doi:10.1016/j. mehy.2019.109357

150. Meyer B, Baranto A, Schils F, et al. Percutaneous interspinous spacer vs decompression in patients with neurogenic claudication: an alternative in selected patients? NEUROSURGERY. 2018;82(5):621-629. doi:10.1093/neuros/nyx326

151. Moojen WA, Arts MP, Jacobs WCH, et al. IPD without bony decompression versus conventional surgical decompression for lumbar spinal stenosis: 2-year results of a double-blind randomized controlled trial. Eur Spine J. 2015;24(10):2295-2305. doi:10.1007/s00586-014-3748-2

152. Smith ZA. Interspinous process device versus standard conventional surgical decompression for lumbar spinal stenosis results in increased reoperation rates and costs without improving patient outcomes. Evid Based Med. 2014;19(4):136. doi:10.1136/ eb-2013-101689

153. Tapp SJ, Martin BI, Tosteson TD, et al. Understanding the value of minimally invasive procedures for the treatment of lumbar spinal stenosis: the case of interspinous spacer devices. Spine J. 2018;18(4):584-592. doi:10.1016/j.spinee.2017.08.246

154. Vinas-Rios JM, Arabmotlagh M, Rahim T, Schmidt S, Sellei RM, Rauschmann M, et al. The importance of interspinous spacers in the treatment of lumbar spinal stenosis. Orthopade. 2019;48(10):831-836. doi:10.1007/s00132-019-03772-z

155. Croe R. It's the effect size stupid. What effect size is and why it is important. British Educational Research Association. 2002

156. Gum JL, Glassman SD, Carreon LY. Clinically important deterioration in patients undergoing lumbar spine surgery: a choice of evaluation methods using the oswestry disability index, 36-item short form health survey, and pain scales: clinical article. J Neurosurg Spine. 2013;19(5):564-568. doi:10.3171/2013.8.SP INE12804

157. Staffa SJ, Zurakowski D. Statistical power and sample size calculations: a primer for pediatric surgeons. Journal of Pediatric Surgery. 2020;55(7):1173-1179. doi:10.1016/j.jpedsurg.2019.05.007

158. Garcia-Canadilla P, Sanchez-Martinez S, Crispi F, Bijnens B, et al. Machine learning in fetal cardiology: what to expect. Fetal Diagn Ther. 2020;47(5):363-372. doi:10.1159/000505021

159. Martínez CR, Lewandrowski K-U, Rugeles Ortíz JG, Alonso Cuéllar GO, Ramírez León JF, et al. Transforaminal endoscopic discectomy combined with an interspinous process distraction system for spinal stenosis. Int J Spine Surg. 2020;14(s3):S4-S12. doi: $10.14444 / 7121$

160. Qin R, Liu B, Hao J, et al. Percutaneous endoscopic lumbar discectomy versus posterior open lumbar microdiscectomy for the treatment of symptomatic lumbar disc herniation: a systemic review and meta-analysis. World Neurosurg. 2018;120:352-362. doi:10.1016/j.wneu.2018.08.236

161. Lee C-H, Choi M, Ryu DS, et al. Efficacy and safety of full-endoscopic decompression via interlaminar approach for central or lateral recess spinal stenosis of the lumbar spine. Spine. 2018;43(24):1756-1764. doi:10.1097/BRS.0000000000002708

162. Phan K, Xu J, Schultz K, et al. Full-endoscopic versus micro-endoscopic and open discectomy: a systematic review and meta-analysis of outcomes and complications. Clin Neurol Neurosurg. 2017;154:1-12. doi:10.1016/j.clineuro.2017.01.003 
163. Ma X-L, Zhao X-W, Ma J-X, Li F, Wang Y, Lu B, et al. Effectiveness of surgery versus conservative treatment for lumbar spinal stenosis: a system review and meta-analysis of randomized controlled trials. Int J Surg. 2017;44:329-338. doi:10.1016/j. ijsu.2017.07.032

164. Ruan W, Feng F, Liu Z, Xie J, Cai L, Ping A, et al. Comparison of percutaneous endoscopic lumbar discectomy versus open lumbar microdiscectomy for lumbar disc herniation: a metaanalysis. Int J Surg. 2016;31:86-92. doi:10.1016/j.ijsu.2016.05.061

165. Li X-C, Zhong C-F, Deng G-B, Liang R-W, Huang C$\mathrm{M}$, et al. Full-endoscopic procedures versus traditional discectomy surgery for discectomy: a systematic review and meta-analysis of current global clinical trials. Pain Physician. 2016;19(3):103-118. doi:10.36076/ppj/2019.19.103

166. He J, Xiao S, Wu Z, Yuan Z, et al. Microendoscopic discectomy versus open discectomy for lumbar disc herniation: a meta-analysis. Eur Spine J. 2016;25(5):1373-1381. doi:10.1007/ s00586-016-4523-3

167. Goldstein CL, Macwan K, Sundararajan K, Rampersaud YR, et al. Perioperative outcomes and adverse events of minimally invasive versus open posterior lumbar fusion: meta-analysis and systematic review. J Neurosurg Spine. 2016;24(3):416-427. doi:10. 3171/2015.2.SPINE14973

168. Concato J, Shah N, Horwitz RI. Randomized, controlled trials, observational studies, and the hierarchy of research designs. N Engl J Med. 2000;342(25):1887-1892. doi:10.1056/ NEJM200006223422507

169. Benson K, Hartz AJ. A comparison of observational studies and randomized, controlled trials. $N$ Engl J Med. 2000;342(25):1878-1886. doi:10.1056/NEJM200006223422506

Funding: The author(s) received no financial support for the research, authorship, and/or publication of this article.
Declaration of Conflicting Interests: The authors report no conflicts of interest related to this work.

Disclaimer: This manuscript is not meant for or intended to endorse any products or push any other agenda other than the associated clinical outcomes with endoscopic spine surgery. The motive for compiling this clinically relevant information is by no means created and/or correlated to directly enrich anyone due to its publication. This publication was intended to substantiate contemporary endoscopic spinal surgery concepts to facilitate technology advancements.The views expressed in this editorial represent those of the authors and no other entity or organization. The authors are accountable for all aspects of the work in ensuring that questions related to the accuracy or integrity of any part of the work are appropriately investigated and resolved.

Corresponding Author: Kai-Uwe Lewandrowski, Center for Advanced Spine Care of Southern Arizona and Surgical Institute of Tucson, 4787 E Camp Lowell Dr, Tucson, AZ 85712, USA; business @ tucsonspine.com

Published 16 February 2022

This manuscript is generously published free of charge by ISASS, the International Society for the Advancement of Spine Surgery. Copyright $\odot 2022$ ISASS. To see more or order reprints or permissions, see http:// ijssurgery.com. 